\title{
Inclusion Removal by Bubble Flotation in a Continuous Casting Mold
}

\author{
LIFENG ZHANG, JUN AOKI, and BRIAN G. THOMAS
}

Fundamentally based computational models are developed and applied to quantify the removal of inclusions by bubbles during the continuous casting of steel. First, the attachment probability of inclusions on a bubble surface is investigated based on fundamental fluid flow simulations, incorporating the turbulent inclusion trajectory and sliding time of each individual inclusion along the bubble surface as a function of particle and bubble size. Then, the turbulent fluid flow in a typical continuous casting mold, trajectories of bubbles, and their path length in the mold are calculated. The change in inclusion distribution due to removal by bubble transport in the mold is calculated based on the computed attachment probability of inclusions on each bubble and the computed path length of the bubbles. In addition to quantifying inclusion removal for many different cases, the results are important to evaluate the significance of different inclusion-removal mechanisms. The modeling approach presented here is a powerful tool for investigating multiscale phenomena in steelmaking and casting operations to learn how to optimize conditions to lower defects.

\section{INTRODUCTION}

NonMETALLIC inclusions in molten steel can lead to serious defects in the final product, and the continuous casting process is the last chance to remove them. Gas injection is commonly applied to many secondary metallurgical processes such as ladle treatment, RH degassing, and submerged entry nozzles (SEN). Although it is well known that gas injection helps to remove inclusions, the mechanisms and removal rates have not been quantified. This work presents fundamental models to quantify the removal of inclusions by bubbles in molten steel and applies them to the continuous casting mold for typical conditions. The problem of modeling the multiple size and time scales involved in inclusion removal by bubbles is handled by separating the phenomena into models at two different scales. A small-scale model is used to quantify the attachment probability of individual inclusions to individual bubbles. The results are then used in a large-scale coupled model of turbulent fluid flow in the entire metallurgical vessel, including the transport of bubbles and inclusions. After briefly reviewing previous work on four relevant topics, the models and corresponding results are presented in three sections: fundamental inclusion-bubble interactions and attachment probabilities, bubble trajectories, and inclusion removal.

\section{INCLUSION ATTACHMENT TO BUBBLES IN MOLTEN STEEL}

\section{A. Defects}

Gas injection processes in steel refining focus on achieving two conditions: fine bubbles and good mixing. ${ }^{[1-6]}$

LIFENG ZHANG, Professor, is with the Department of Materials Science and Engineering, Norwegian University of Science and Technology, Høgskoleringen 8, Alfred Getz vei 2, N-7491 Trondheim, Norway. Contact e-mail: lifeng.zhang@material.ntnu.no JUN AOKI, formerly a Visiting Scholar, with the University of Illinois at Urbana-Champaign, $1206 \mathrm{~W}$. Green Street, Urbana, IL 61801, U.S.A., is now Researcher with Nippon Steel, Japan. BRIAN G. THOMAS, Professor, is with the University of Illinois at Urbana-Champaign, 1206 W. Green Street, Urbana, IL 61801, U.S.A.

Manuscript submitted August 4, 2005.
During steel secondary refining, finer bubbles provide a larger gas/liquid interfacial area and higher attachment probability of inclusions to bubbles. ${ }^{[3,6]}$ Good mixing enhances the efficiency of the transfer of the alloy elements. Bubbles injected into the SEN and continuous casting mold affect steel quality in several ways:

(1) Helping to reduce nozzle clogging

(2) Influencing the flow pattern in the mold

(3) Generating top-surface-level fluctuations and even slag emulsification if the gas flow rate is too large

(4) Capturing inclusions moving within the molten steel, agglomerating them, and removing some of them into the top $\operatorname{slag}^{[3,7,8,9]}$

(5) Entrapping bubbles and inclusion clusters into the solidified shell, eventually leading to line defects such as surface slivers, blisters, pencil pipes, or internal defects in the rolled product. ${ }^{[7,8,10,11,12]}$

Aided by surface tension forces from nonwetting contact, most solid inclusions tend to collect on surfaces such as bubbles (Figure 1). ${ }^{[13,14]}$ Line defects on the surface of finished strip products are several tens of micrometers to millimeter in width and as long as 0.1 to $1 \mathrm{~m} \cdot{ }^{[15]}$ Serious "sliver" defects result from clusters of nonmetallic inclusions caught near the surface of the slab $(<15 \mathrm{~mm}$ from the surface). If the surface defects contain bubbles, they are called pencil pipe, blow holes, blisters, ${ }^{[15]}$ or pores. After rolling of low-strength steels for exposed automotive applications, for example, the bubbles are elongated, and during annealing gas expansion can generate internal pressure that raises the surface, creating an ugly surface streak. This tubular surface defect has a smooth, slightly raised surface, typically $\sim 1 \mathrm{~mm}$ wide and 150 to $300 \mathrm{~mm}$ long (Figure 2). ${ }^{[15,16,17]}$

\section{B. Inclusion-Bubble Interaction}

The process of inclusion removal by attachment to gas bubbles is influenced by various factors, including the liquid flow and the inclusion, bubble, liquid steel, and slag properties. The overall process is complicated by the coalescence and breakup of bubbles in the bubble swarm. 


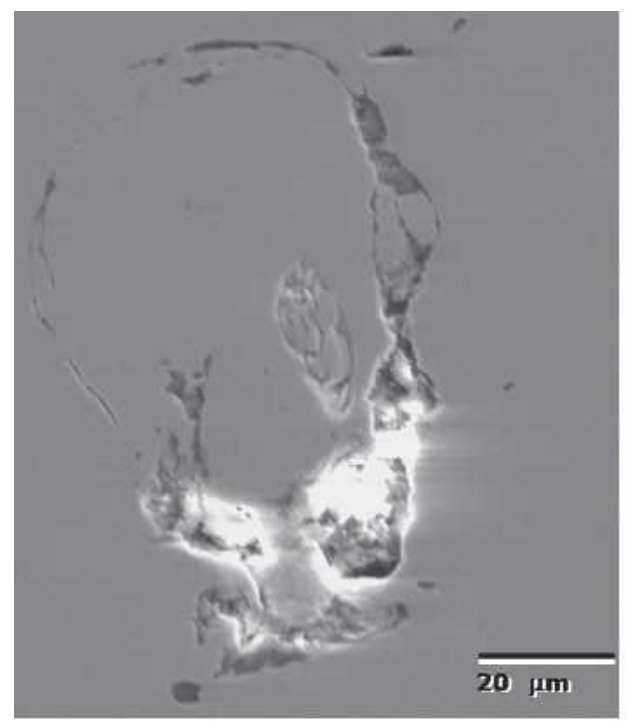

(a)

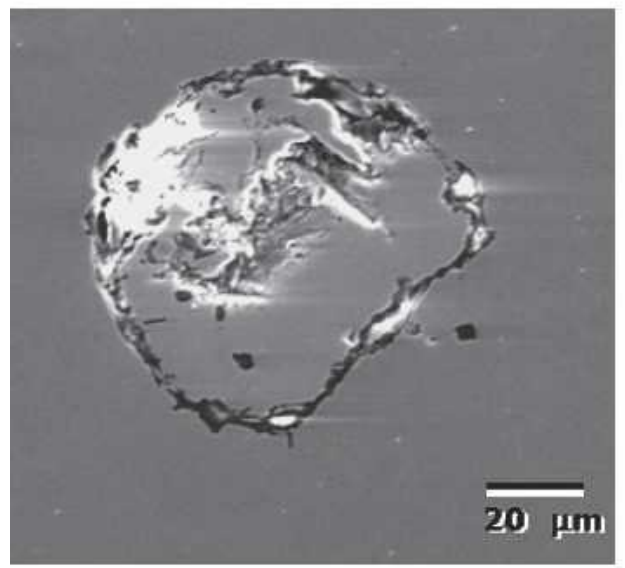

(c)

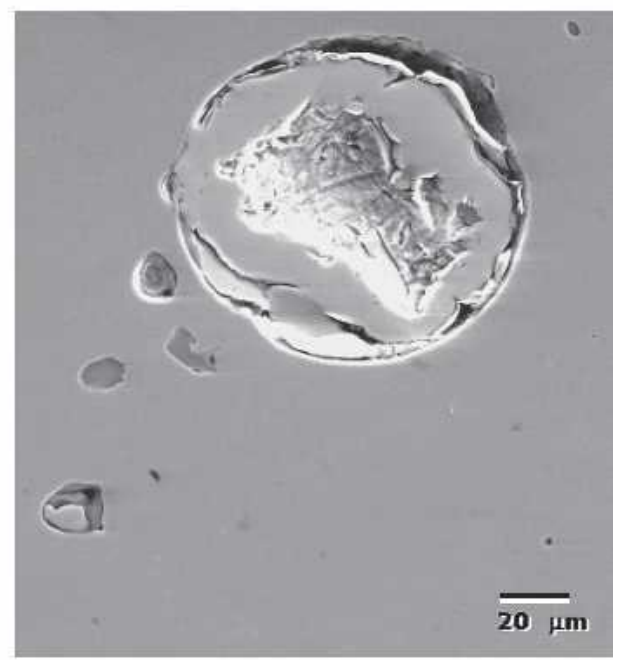

(b)

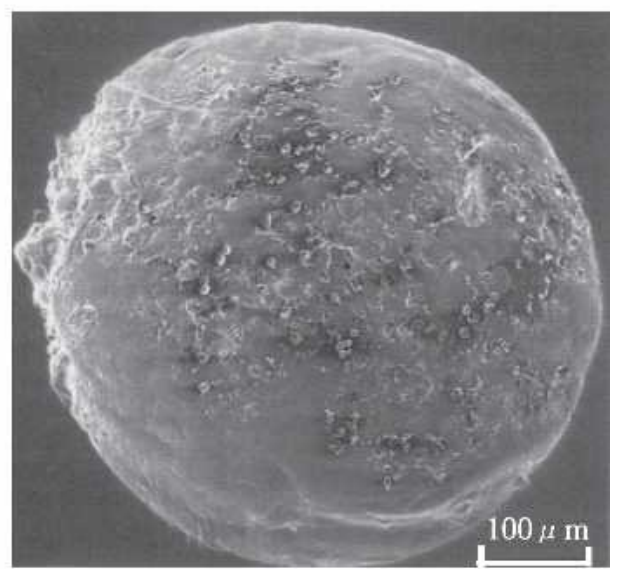

(d)

Fig. 1-Inclusions outlining the former surface of bubbles captured in ingot steel $(a)$ through $(c)^{[13]}$ and in continuous cast steel $(d){ }^{[14]}$

Although several papers have been written on particle removal by gas bubbles flotation in water modeling, ${ }^{[1,18-21]}$ little research work has been carried out on hot modeling. ${ }^{[22,23,24]}$ Szekely investigated the removal of solid particles from molten aluminum during the spinning nozzle flotation process. ${ }^{[22]}$ Okumura et al. studied the removal of $\mathrm{SiO}_{2}$ inclusions from molten $\mathrm{Cu}$ to the slag under gas injection stirring conditions. ${ }^{[23]}$ Miki et al. investigated inclusion removal during steel RH degassing, considering bubble flotation as one of the inclusion-removal methods. ${ }^{[25]}$ There is no complete fundamental knowledge concerning the inclusion removal by bubble flotation in liquid steel systems. However, Zhang et al. extensively reviewed and studied the interaction between bubble and solid inclusion particle in the molten steel in $2000,{ }^{[3]}$ including the particle behavior near liquid gas surface, attachment process, and inclusion removal by bubble flotation. The overall process of attaching an inclusion to a gas bubble in molten steel proceeds through the following steps. First, the inclusion approaches the gas bubble, and collides if it gets close enough. If the thin film of liquid between the particle and the bubble decreases to less than a critical thickness, it will suddenly rupture, causing the inclusion to attach permanently to the surface of the bubble during the collision. Otherwise, if it slides along the surface of the bubble for a long enough time, the thin film can drain away and rupture, again leading to inclusion attachment. Otherwise, the inclusion will move away and detach from the bubble.

The interaction time between the bubble and the inclusion $t_{I}$ includes the time while the inclusion collides with the bubble (collision time) and possibly also the time where it slides across its surface (sliding time). The collision time $t_{c}$ starts with the deformation of the bubble by the inclusion and finishes at the instant of restoration of the bubble to its original size. Zhang reviewed different models of the collision time and concluded that the Ye and Miller model ${ }^{[26]}$ can be used. ${ }^{[3]}$ Ye and Miller ${ }^{[26]}$ give the collision time as:

$$
t_{c}=\left(\frac{d_{p}^{3} \rho_{p}}{12 \sigma}\right)^{1 / 2}\{\pi+\phi\}
$$

The collision time depends mainly on the inclusion size and is independent of the bubble size. 


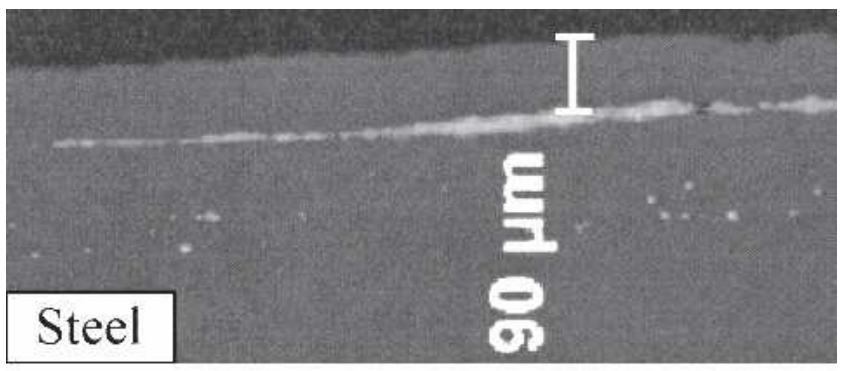

(a)

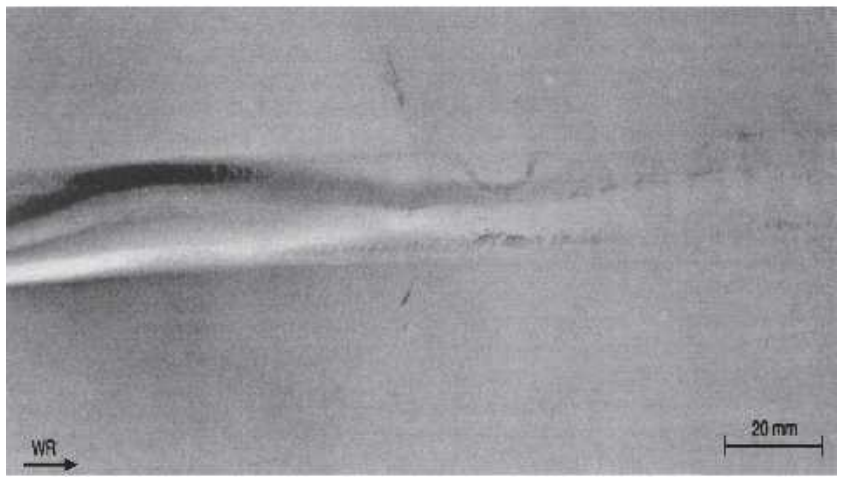

(b)

Fig. 2-Inclusion sliver in longitudinal section of a rolled sheet product $(a)^{[17]}$ and pencil pipe lamination defect on a steel sheet $(b) .{ }^{[15]}$

$$
\phi=2 \arcsin \left[1+\frac{12 u_{R}^{2} \sigma \rho_{p}}{d_{p}^{3} g^{2}\left(\rho_{p}-\rho\right)^{2}}\right]^{-1 / 2}
$$

The value of $\phi$ as a function of particle diameter $d_{p}$ and the relative velocity between the bubble and the inclusion $u_{R}$ is shown in Figure 3, which indicates $0<\phi<\pi$. Only when the inclusion is larger than $100 \mu \mathrm{m}$ and the relative velocity between the inclusion and the bubble is as small as $10^{-4} \mathrm{~m} / \mathrm{s}$ does $\phi$ approach $\pi$. If $d_{p}<100 \mu \mathrm{m}, u_{R}>0.1 \mathrm{~m} / \mathrm{s}$, and $\phi<0.0038<<\pi$, then the collision time of the inclusion to the bubble in our liquid steel system can be simplified into

$$
t_{c}=\pi\left(\frac{d_{p}^{3} \rho_{p}}{12 \sigma}\right)^{1 / 2}
$$

The film drainage time $t_{F}$ is the time required for the drainage of the liquid film between the bubble and the inclusion until a critical film thickness is reached and rupture occurs. Schulze ${ }^{[27]}$ derived the rupture time of the film formed between a solid particle and a gas bubble as

$$
t_{F}=\frac{3}{64} \mu \frac{\alpha^{2}}{C \sigma h_{\mathrm{Cr}}^{2}} d_{P}^{3}
$$

where $\alpha$, the angle (in rad) for the transition of the spherically deformed part of the bubble surface to the nonspherically deformed part, is given by: ${ }^{[3]}$

$$
\alpha=\arccos \left(1-1.02\left(\frac{\pi d_{p} \rho_{p} u_{\mathrm{R}}^{2}}{12 \sigma}\right)^{1 / 2}\right)
$$

The critical thickness of liquid film for film rupture is given by: ${ }^{[3]}$

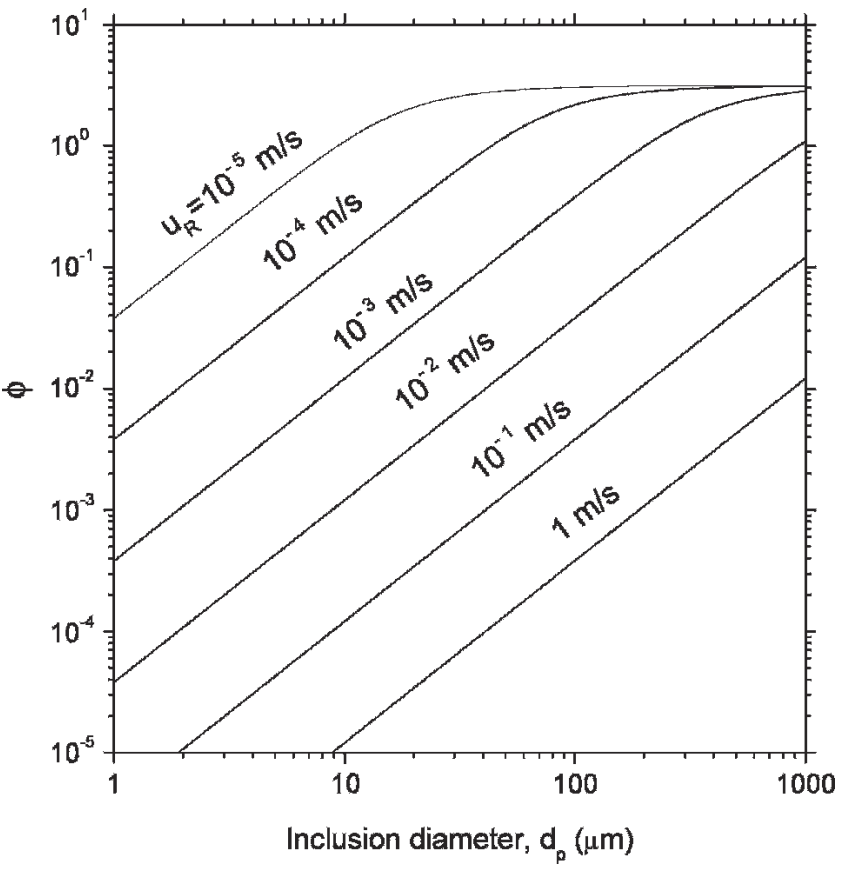

Fig. 3-The dimensionless factor $\phi$ (Eq. [2]) for the collision time as a function of inclusion diameter and the relative velocity between the inclusion and the bubble.

$$
h_{\mathrm{Cr}}=2.33 \times 10^{-8}[1000 \sigma(1-\cos \theta)]^{0.16}
$$

In the current study, $u_{\mathrm{R}}$ is assumed to equal the bubble terminal velocity $u_{\mathrm{B}}$.

When the inclusion collides with and slides on the bubble surface, the bubble surface is deformed, which affects the formation and rupture of the film. Thus, $\alpha$ is influenced both by bubble property and by inclusion property. The deduction of Eq. [5] is detailed in Zhang's paper. ${ }^{[3]}$

After a particle has broken through the liquid film and reached the gas bubble, it will reside stably at the gas/liquid interface regardless of the contact angle. Subsequent detachment is difficult, especially for particles that are small relative to the bubble size.

The process of inclusion removal by gas bubbles is characterized by the attachment probability. This process is influenced by many factors, including the turbulent fluid flow of the molten steel, the shape and size of both the bubble and the inclusion, surface tension effects, and bubbleremoval rates, which are affected by slag properties. The attachment probability is the fraction of inclusions that pass the rising bubble and attach to it. When turbulence levels are small, it can be defined as:

$$
P=\frac{N_{O}}{N_{T}}=\left(\frac{d_{O S}}{d_{B}+d_{P}}\right)
$$

where $N_{O}=$ the number of inclusions attaching to the bubble and $N_{T}=$ the number of inclusions in the column of fluid swept by the moving bubble with diameter $d_{B}+d_{P}$. Without the stochastic effect of turbulence, only particles starting within a critical distance from the bubble axis $d_{O S}$ will be entrapped (Figure 4(a)). 


\section{Bubble Size}

Gas can be injected into the molten steel by various devices, such as tuyeres, lances, and porous refractory plugs, which govern the initial bubble size. Large bubbles can break up according to the local turbulence level. The size of the largest surviving bubbles can be estimated by the forces imposed on the bubble. ${ }^{[3]}$ The average equivalent size of bubbles to survive the turbulence in secondary steelrefining processes is predicted to be 10 to $20 \mathrm{~mm}^{[3,28]}$ and $\sim 5 \mathrm{~mm}$ in the CC mold. ${ }^{[3]}$ Bubble shape changes with size. The aspect ratio of the bubble $e$ varies according to the following empirical relationship: ${ }^{[29]}$

$$
e=1+0.163 E^{0.757}
$$

where $E o=$ the Eötvös number, which represents the ratio between the buoyancy and surface tension forces.

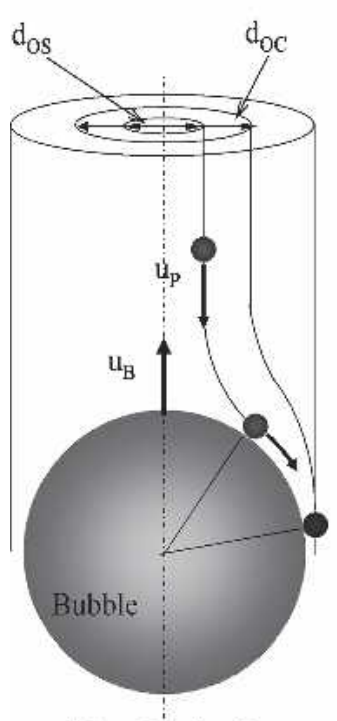

Non-Stochastic

(a)

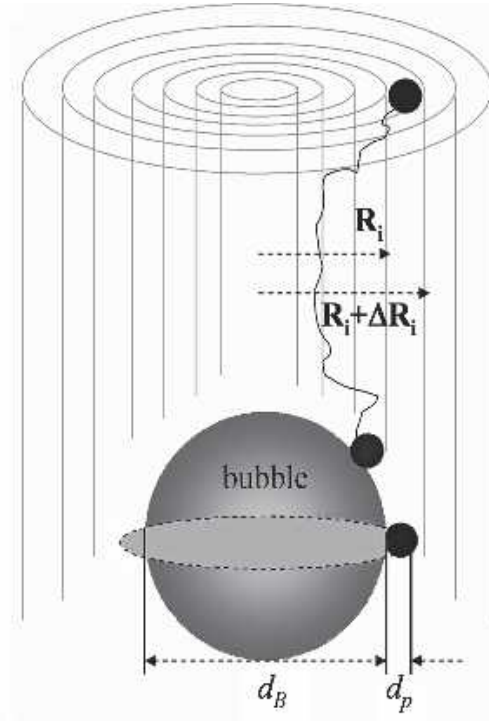

Stochastic

(b)
Fig. 4-Schematic of the attachment probability of inclusions to the bubble surface.

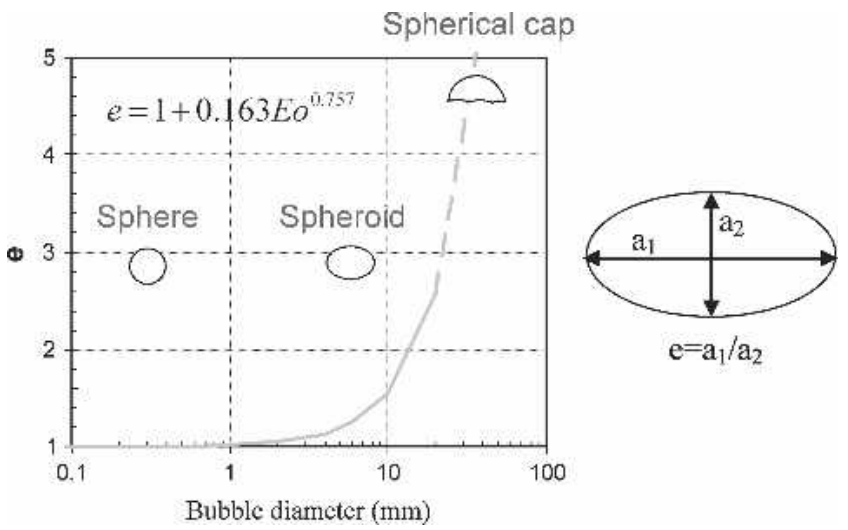

Fig. 5-Bubble shape characterized by its aspect ratio $(e)$ as a function of its size. ${ }^{[29]}$
Figure 5 shows the aspect ratio $e$ of bubbles in molten steel, indicating that bubbles smaller than $3 \mathrm{~mm}$ are spherical, bubbles 3 to $10 \mathrm{~mm}$ are spheroidal, and bubbles larger than $10 \mathrm{~mm}$ are spherical-cap shaped. ${ }^{[30,31,32]}$ Most bubbles in the continuous casting mold are nearly spherical due to their size of $\sim 5 \mathrm{~mm}$. $^{[33-36]}$

The shape of the bubble also depends on the ratio of the turbulent pressure fluctuation to the capillary pressure, which is related to the Weber number. If the bubble Weber number exceeds a critical value, the bubble will break up. Thus, bubble size decreases with increasing stirring intensity of the liquid phase,$^{[3]}$ according to: ${ }^{[37]}$

$$
d_{\mathrm{Bmax}} \approx W e_{\text {Crit }}^{0.6}\left(\frac{\sigma \times 10^{3}}{\rho \times 10^{-3}}\right)^{0.6}(\varepsilon \times 10)^{-0.4} \times 10^{-2}
$$

where $d_{\mathrm{Bmax}}=$ the maximum bubble size in $\mathrm{m}, \varepsilon$ is in $\mathrm{W} / \mathrm{t}$, and the critical Weber number $W e_{\text {Crit }} \approx 0.59$ to 1.3 (Figure 6 ). The stirring intensities of various metallurgical systems are also shown in this figure. ${ }^{[3]}$ The highly turbulent flow in the SEN will break up any gas pockets into fine bubbles $\sim 5 \mathrm{~mm}$ in diameter. ${ }^{[33-36]}$ It was reported that the newly developed swirl SEN generates a larger energy dissipation rate in the nozzle. ${ }^{[38-41]}$ According to Eq. [9], this kind of nozzle may generate smaller bubbles.

\section{Bubble Terminal Velocity}

The terminal velocity of bubbles rising in molten steel is difficult to measure accurately. The density, viscosity, and surface tension of the liquid affect the bubble terminal velocity, as do bubble size and the turbulent fluid flow characteristics. Figure 7 shows the terminal velocities of gas bubbles in the molten steel as calculated by different models. ${ }^{[3]}$ A smoothed mean of the bubble velocity predicted by these models is compared with the predictions of the model in the current work (presented later).

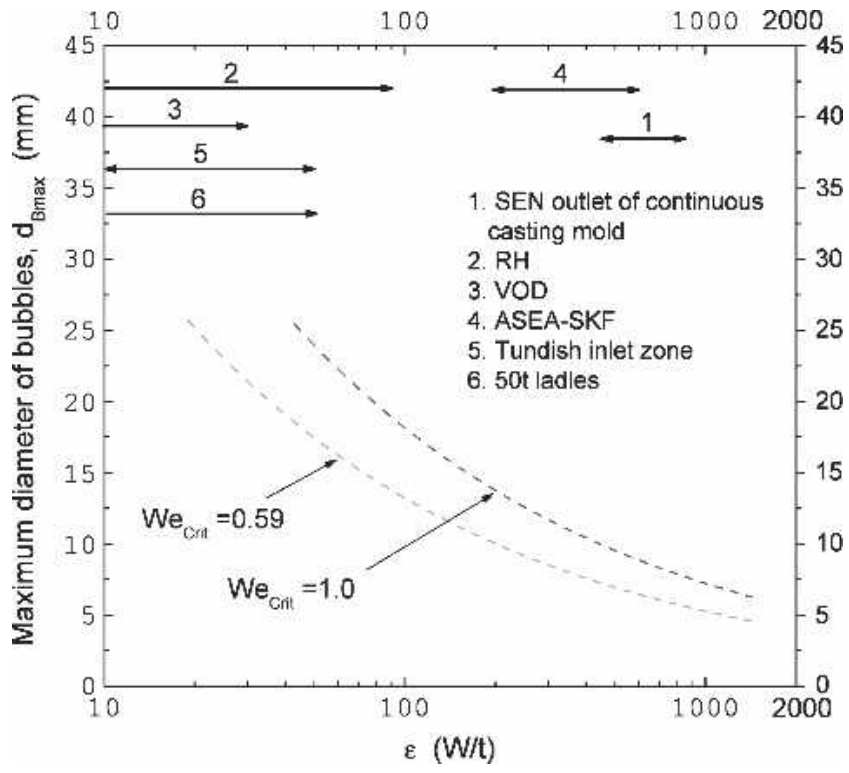

Fig. 6-Maximum argon bubble size in turbulent molten steel with bulk stirring powers of different vessels. ${ }^{[3]}$ 


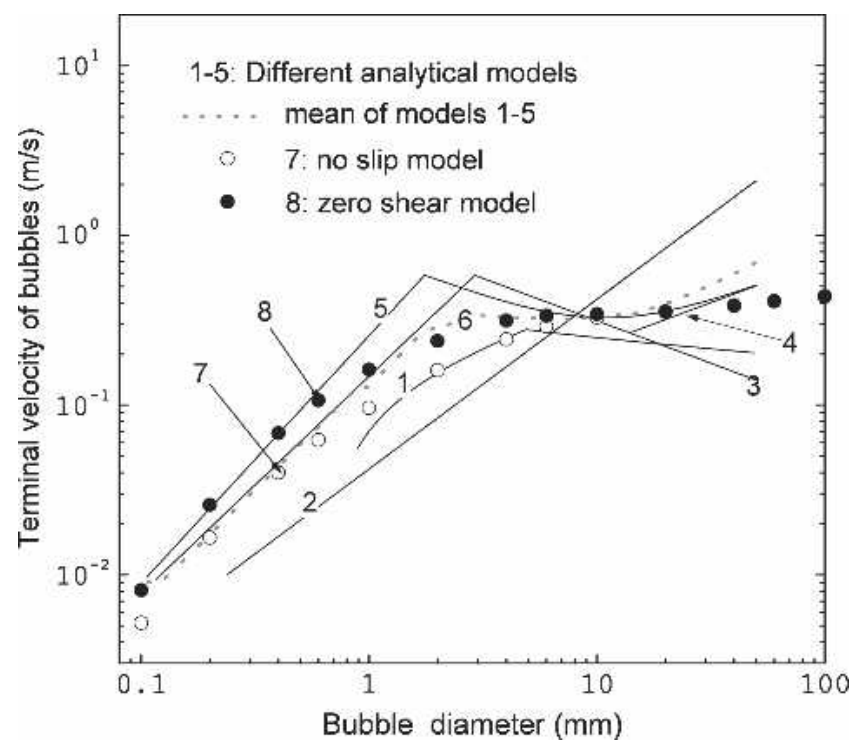

Fig. 7-Bubble terminal rising velocity variation with stirring power; analytical models 1 to 5 refer to Zhang's study. ${ }^{[3]}$

The terminal velocity of a bubble can be calculated from a force balance between the buoyancy force and the drag force acting on the bubble. The buoyancy force is expressed by:

$$
F_{B}=\frac{\pi d_{B}^{3}}{6}\left(\rho-\rho_{g}\right)
$$

and the total drag force $F_{D}$ is calculated by integrating over the surface of the bubble:

$$
F_{D}=\int_{S} \tau_{i j} d A=\int_{S}\left[-p \delta_{i j}+\mu\left(\frac{\partial u_{j}}{\partial x_{i}}+\frac{\partial u_{i}}{\partial x_{j}}\right)\right] d A
$$

The drag force depends on the size, velocity, and surface condition of the bubble, while the buoyancy force only depends on the bubble size. By applying $F_{B}=F_{D}$ for a given size bubble and surface condition, the terminal velocity of the bubble can be obtained. For a free bubble, a zero shear condition is the most appropriate boundary condition on the bubble surface. The alternative surface boundary condition of zero velocity ("no slip") is more appropriate for bubbles with rigid surfaces, such as those caused by surface-active elements or covering the surface with particles. Figure 7 shows that the terminal velocity of bubbles calculated with the zero shear surface condition agrees well with the mean of other analytical models. Thus, the mean value of models 1 to 5 is used as the terminal velocity of bubbles when the fluid flow around bubbles is simulated. A peak occurs at a bubble diameter of $3 \mathrm{~mm}$, where the bubble shape starts to change from spherical to ellipsoidal. Ellipsoidal bubbles (3 to $10 \mathrm{~mm}$ ) have similar velocity. For bubbles larger than $10 \mathrm{~mm}$, terminal velocity increases rapidly with increasing size due to their spherical-cap shape.

\section{INCLUSION ATTACHMENT TO GAS BUBBLES}

\section{A. Model Formulation}

To determine the interaction time and the attachment probability of inclusions to the bubble surface, a computa- tional simulation of turbulent flow around an individual bubble and a simulation of inclusion transport through the flow field were developed. First, the steady turbulent flow of molten steel around an argon bubble was calculated by solving the continuity equation, Navier-Stokes equations, and the standard equations for turbulent energy and its dissipation rate transport in two dimensions, assuming axisymmetry.

The domain included 15 to 20 times bubble diameter distance before and after the bubble using the finite differentiation code FLUENT. ${ }^{[42]}$ Possible deformation of the bubble shape by the flow and inclusion motion is ignored. The bubble is fixed and the inlet velocity and far-field velocity condition are set to the bubble terminal velocity, assuming a suitable turbulent energy and dissipation rate, and a far-field pressure outlet.

Both zero velocity and zero shear stress boundary conditions at the fluid-bubble interface were applied and the results were compared. The terminal velocities of bubbles were the mean value in Figure 7 . The zero velocity condition produces slightly lower velocities for small spherical bubbles and higher velocities for larger spherical bubbles. The zero shear condition was assumed for the rest of the results in this work. The trajectory of each inclusion particle was then calculated from the computed velocity field by integrating the following particle velocity equation, which considers the balance between drag and buoyancy forces:

$$
\begin{aligned}
\frac{d u_{p i}}{d t}= & \frac{18 \mu}{\rho_{P} d_{p}^{2}} \frac{C_{D} \operatorname{Re}_{p}}{24}\left(u_{i}-u_{p i}\right)+\frac{\rho_{p}-\rho}{\rho} g_{i} \\
& +\frac{1}{2} \frac{\rho}{\rho_{P}} \frac{d}{d_{t}}\left(u_{i}-u_{p i}\right)+\frac{\rho}{\rho_{p}} u_{i} \frac{\partial u_{i}}{\partial x_{i}}
\end{aligned}
$$

The drag force coefficient is given by:

$$
C_{D}=\frac{24}{\operatorname{Re}_{p}}\left(1+0.186 \operatorname{Re}_{p}^{0.6529}\right)
$$

The first term in Eq. [12] is the drag force per unit particle mass, the second term is the gravitational force, the third term is the "virtual mass" force ${ }^{[4]}$ accelerating the fluid surrounding the particle, and the fourth term is the force stemming from the pressure gradient in the fluid. The lift force is ignored in the current study. For solid inclusions $(<300 \mu \mathrm{m})$ in liquid steel, the lift force is not important. However, for argon bubbles in liquid steel, the lift force is important, ${ }^{[4,43]}$ though not as important as the drag force and gravitational force. In the future simulation of bubble motion in the liquid steel, the lift force will be included.

To incorporate the "stochastic" effect of turbulent fluctuations on the particle motion, this work uses the "random walk" model in FLUENT. ${ }^{[44]}$ In this model, particle velocity fluctuations are based on a Gaussian-distributed random number chosen according to the local turbulent kinetic energy. The random number is changed, thus producing a new instantaneous velocity fluctuation, at a frequency equal to the characteristic lifetime of the eddy. The instantaneous fluid velocity is then given by:

$$
\begin{gathered}
u=\bar{u}+u^{\prime}, \\
u^{\prime}=\xi \sqrt{\overline{u^{\prime 2}}}=\xi \sqrt{2 k / 3}
\end{gathered}
$$

As boundary conditions, inclusions reflect if they touch the surface of the bubble. Attachment between the inclusion 
and the bubble was determined by the following steps. If the normal distance from the inclusion center to the surface of the bubble quickly becomes less than the inclusion radius, then collision attachment takes place. This was rare. Then, the interaction time between the bubble and the inclusion $t_{I}$ is calculated from the inclusion centerline trajectory results by tracking the sliding time that elapses while the distance from the inclusion center to the surface of the bubble is less than the inclusion radius. Then, if $t_{I}>t_{F}$, the inclusion will be attached to the surface of the bubble.

The attachment probability is then calculated using Eq. [7] by injecting several thousand inclusions uniformly with the local velocity into the domain in a column with diameter $d_{B}+d_{p}$ for nonstochastic cases.

The classic attachment probability schematic given in Figure 4(a) does not apply in turbulent conditions. Due to the stochastic effect of turbulence, some inclusions inside the column of $d_{O S}$ may not interact with the bubble. On the other hand, other inclusions even far outside the column $d_{B}+$ $d_{p}$ may interact, collide, and attach onto the bubble surface. To model this effect, inclusions were injected into a column that was 15 to 20 times of the bubble diameter to compute this accurately. Then the attached probability (Figure 4(b)) was obtained by:

$$
P=\frac{\sum_{i} P_{i} A_{i}}{A_{B+P}}=\frac{\sum_{i}\left[\frac{N_{O, i}}{N_{T, i}}\left(\pi\left(R_{i}+\Delta R\right)^{2}-\pi R_{i}^{2}\right)\right]}{\frac{\pi\left(d_{B}+d_{p}\right)^{2}}{4}}
$$

where $i=$ the number of the annular area at which the inclusions are injected.

In the current investigation, the following parameters are used: $\rho=7020 \mathrm{~kg} / \mathrm{m}^{3}, \rho_{P}=2800 \mathrm{~kg} / \mathrm{m}^{3}, \rho_{g}=1.6228 \mathrm{~kg} / \mathrm{m}^{3}$, $\sigma=1.40 \mathrm{~N} / \mathrm{m}, \theta=112 \mathrm{deg}, \mu=0.0067 \mathrm{~kg} / \mathrm{m} \cdot \mathrm{s}, d_{p}=1$ to $100 \mu \mathrm{m}$, and $d_{B}=1$ to $10 \mathrm{~mm}$. These parameters represent typical spherical solid inclusions such as alumina in molten steel.

\section{B. Fluid Flow and Inclusion Motion Around a Bubble}

Figure 8 shows the fluid flow pattern behind a rigid sphere $(1.5 \mathrm{~mm}$ in diameter) in water. The simulation of the current work agrees well with the measurement. ${ }^{[45]}$ There is a recirculation region or swirl behind the solid particle. This swirl is not observed in fluid flow around a free bubble (zero shear velocity) (Figure 9). Figure 9 shows the fluid flow pattern and trajectories of $100-\mu \mathrm{m}$ inclusions around a 5-mm bubble in molten steel. The tracer particles $(7020$ $\mathrm{kg} / \mathrm{m}^{3}$ density) follow the stream lines and tend to touch the surface of the bubble at the top point (exactly halfway around the bubble) (Figure 9(a)). Particles with density larger than that of the liquid, such as solid particles in water in mineral processing, tend to touch the bubble before the top point (Figure 9(b)), while lighter particles, such as inclusions in the molten steel, tend to touch the bubble after the top point (Figure 9(c)). Stochastic fluctuation of the turbulence makes the inclusions very dispersed, so attachment may occur at a range of positions (Figure 9(d)).

The average turbulent energy in the bulk of the liquid has little effect on the local turbulent energy distribution around the bubble. As shown in Figure 10, (a) has four orders of magnitude larger average turbulent energy than in the farfield liquid (b), but it has slightly smaller local turbulent energy around the bubble. This is because (a) has a lower bubble terminal velocity than (b). However, the average turbulent energy has a great effect on the inclusion motion, according to Eqs. [14] and [15].

During the motion of bubbles in molten steel, the fluid flow pattern around the bubble will change as inclusions become attached (Figure 11). In this figure, the points of inclusions at and near the bubble surface are just randomly chosen; no real coagulation model is used. Because the bubble surface is considered to be free surface, inclusions attached to the front half surface of the bubble will slide to the rear of the bubble (Figure 11(d)). A recirculation region behind the bubble is generated even for only five $50-\mu \mathrm{m}$ inclusions attached on the surface of the bubble. This recirculation does not exist behind a bubble that is free from attached inclusions. Thus, the fluid flow pattern around a bubble with attached solid inclusions is more like that around solid particles, such as shown in Figure 8. Figure 12 indicates that high turbulent energy levels exist around the inclusions attached on a bubble, and the turbulent energy in the wake of the bubble becomes smaller with more attached inclusions. The turbulence level around the bubble in turn affects inclusion attachment (Eqs. [14] and [15]). Also, forces on the particles will push them around the bubble surface toward the back of the bubble. With the current attachment model, these phenomena are not included, so further study is needed.

\section{Inclusion Attachment Probability to Bubbles}

The calculated collision times (Eq. [3]) and film drainage times (Eq. [4]) of inclusions onto bubbles are shown in Figure 13 for various inclusions in molten steel. Figure 13(a) shows that for wetting inclusions (with small contact angle) the film rupture time is very large, but for nonwetting inclusions usually encountered in steelmaking (contact angle $>90 \mathrm{deg}$ ) the film rupture time is very short (60 to $67 \mu \mathrm{s})$. Figure 13(b) indicates that the collision time and film drainage time both increase with increasing inclusion size, but the film drainage time increases more steeply. For inclusions smaller than $\sim 10 \mu \mathrm{m}$, the collision time is larger than the film drainage time; thus, inclusions will attach on the surface of the bubble once colliding with it, and this attachment is independent of the sliding process.

The calculated normal distances from the center of $100-\mu \mathrm{m}$ inclusions to the surface of a 1-mm bubble are shown in Figure 14(a) as function of time during the approach of inclusions to this bubble. The time interval when the distance is less than the inclusion radius $(50 \mu \mathrm{m})$ is the interaction time (sliding time) between the inclusion and the bubble (Figure 14(b)). If this sliding time is larger than the film rupture time (Eq. [4] and Figure 13), the inclusion is stably attached to the bubble surface. Larger inclusions require greater interaction times to attach, on the order of millisecond.

The calculated attachment probability of inclusions $\left(d_{P}=\right.$ $5,10,20,35,50,70,100 \mu \mathrm{m})$ to bubbles $(1,2,4,6,10 \mathrm{~mm})$ are shown in Figure 15(a), based on trajectory calculations of inclusions without considering the stochastic effect. To 


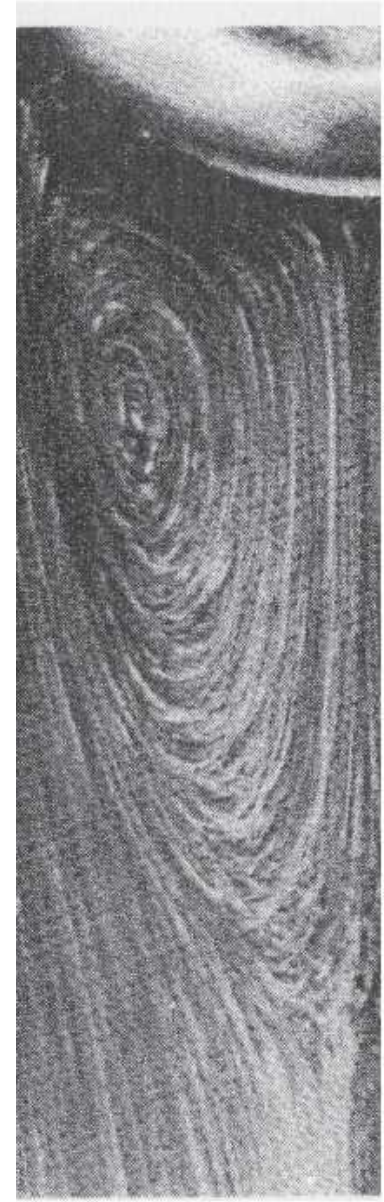

(a)

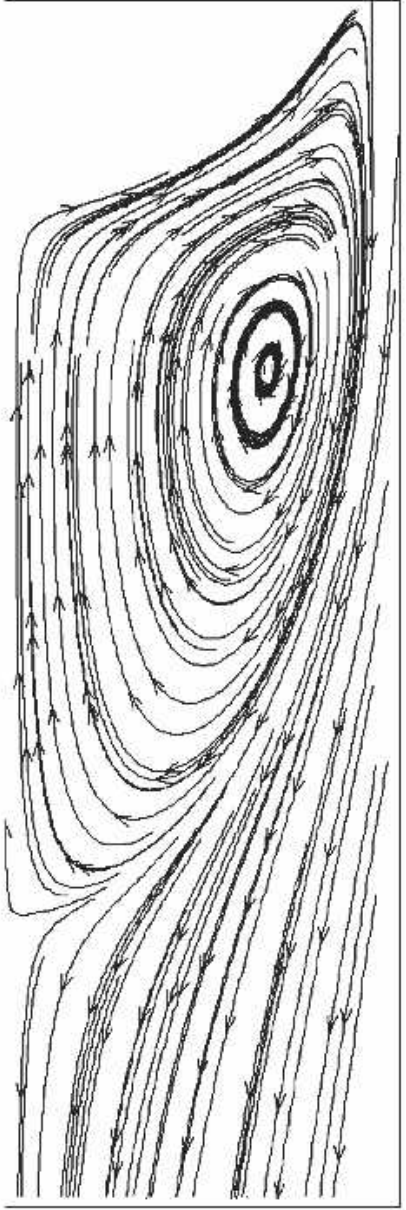

(b)

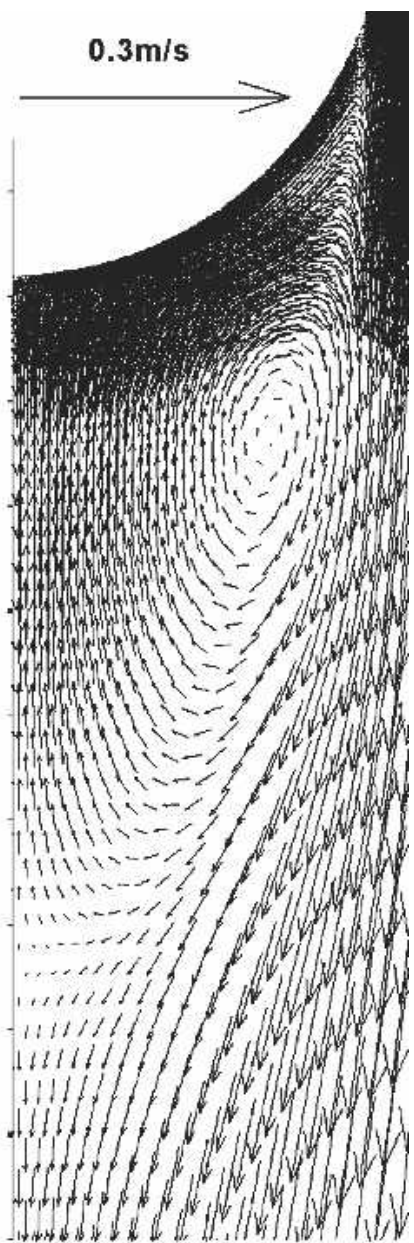

(c)

Fig. 8-Fluid flow behind a rigid sphere $\left(1.5 \mathrm{~mm}\right.$ in diameter) in water. (a) Experiment. ${ }^{[45]}(b)$ Streamline by simulation. $(c)$ Velocity by simulation.

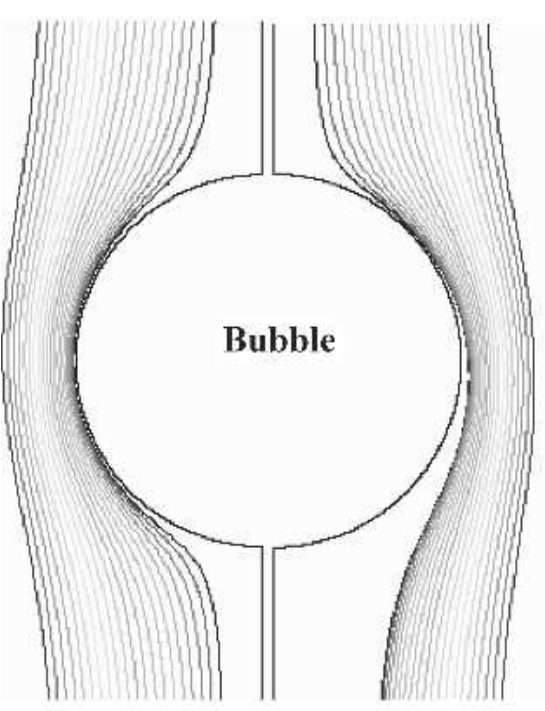

(a)

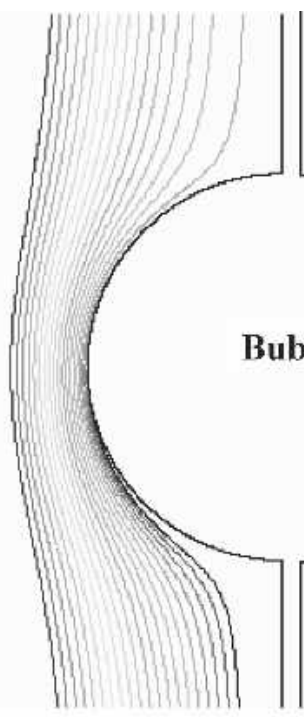

(c)

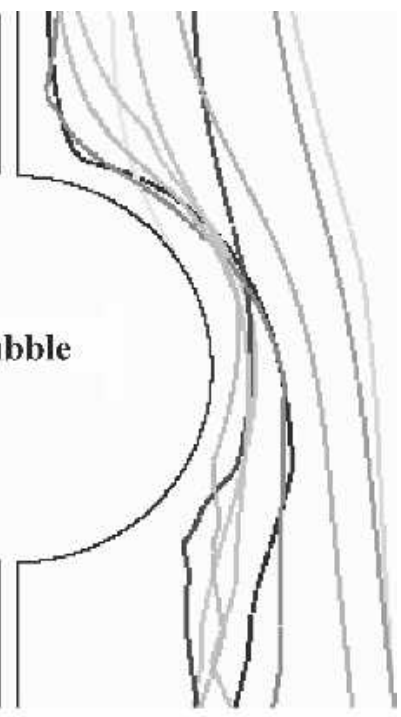

(d)

Fig. 9-Fluid flow and trajectories of $100-\mu \mathrm{m}$ inclusions around a $5-\mathrm{mm}$ bubble in the molten steel with density of $7020 \mathrm{~kg} / \mathrm{m}^{3}$. (a) Neutral-buoyancy particles $\left(7020 \mathrm{~kg} / \mathrm{m}^{3}\right)$. (b) Denser particles $\left(14,040 \mathrm{~kg} / \mathrm{m}^{3}\right)$. (c) Inclusions $\left(2800 \mathrm{~kg} / \mathrm{m}^{3}\right)$. (d) Random walk of inclusions. 


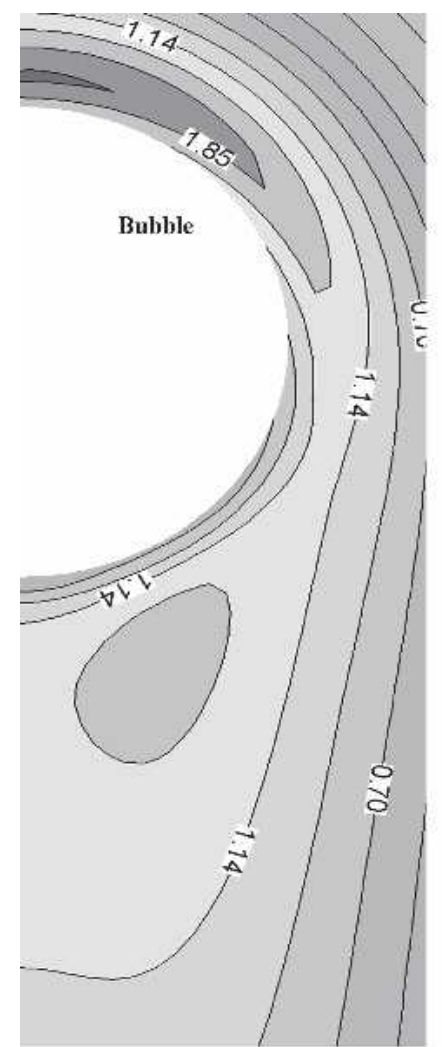

(a)

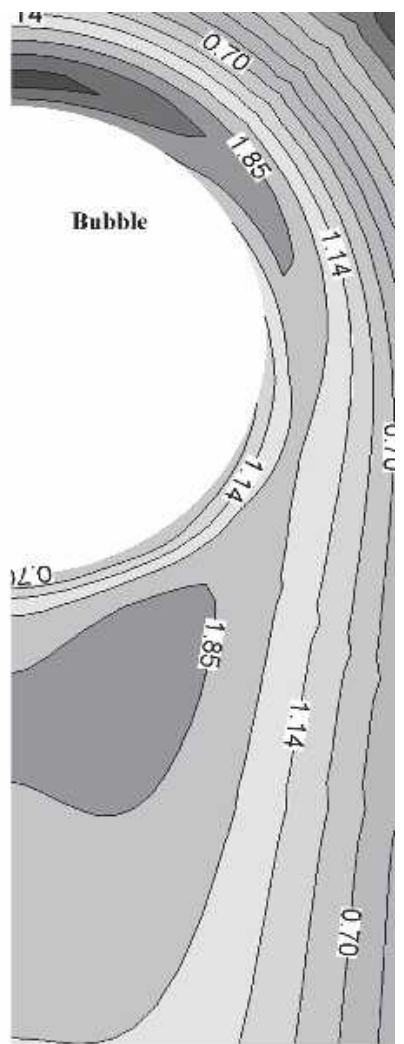

(b)
Fig. 10-Turbulent energy distribution $\left(1000 \mathrm{k}\right.$, in $\left.\mathrm{m}^{2} / \mathrm{s}^{2}\right)$ around a $1-\mathrm{mm}$ bubble. (a) Bulk turbulent energy $1.62 \times 10^{-4} \mathrm{~m}^{2} / \mathrm{s}^{2}$, and its dissipation rate $1.43 \times 10^{-3} \mathrm{~m}^{2} / \mathrm{s}^{3}, 0.129 \mathrm{~m} / \mathrm{s}$ bubble terminal velocity. (b) Bulk turbulent energy $1.06 \times 10^{-8} \mathrm{~m}^{2} / \mathrm{s}^{2}$, and its dissipation rate $2.74 \times$ $10^{-7} \mathrm{~m}^{2} / \mathrm{s}^{3}, 0.162 \mathrm{~m} / \mathrm{s}$ bubble terminal velocity.

compute attachment rates for a continuous size distribution of inclusions and bubbles, regression was performed on these probabilities (Table I). The regression equation obtained, Eq. [17], is included in Figure 15:

$$
P=C_{A} d_{p}^{C_{B}}
$$

where $C_{A}$ and $C_{B}$ are

$$
\begin{gathered}
C_{A}=0.268-0.0737 d_{B}+0.00615 d_{B}^{2} \\
C_{B}=1.077 d_{B}^{-0.334}
\end{gathered}
$$

where $d_{B}$ is in mm and $d_{p}$ is in $\mu \mathrm{m}$.

Eq. [17] should be used under the following conditions: bubble size is in the range of 1 to $10 \mathrm{~mm}$, and bulk turbulent energy level is less than $10^{-2} \mathrm{~m}^{2} / \mathrm{s}^{2}$. The attachment probability of inclusions to the surface of the bubble for processes with turbulent energy of more than $10^{-2} \mathrm{~m}^{2} / \mathrm{s}^{2}$, such as argon stirred ladles, is investigated elsewhere. ${ }^{[43]}$ In a continuous casting mold, the bubble size is less than $5 \mathrm{~mm}$ and the turbulent energy is in the order of $10^{-3} \mathrm{~m}^{2} / \mathrm{s}^{2}$; hence, Eq. [17] can be used.

Figure $15(\mathrm{~b})$ indicates that the regression equation matches roughly the numerical simulations. Figure 15(c) shows the calculated attached attachment probability as a

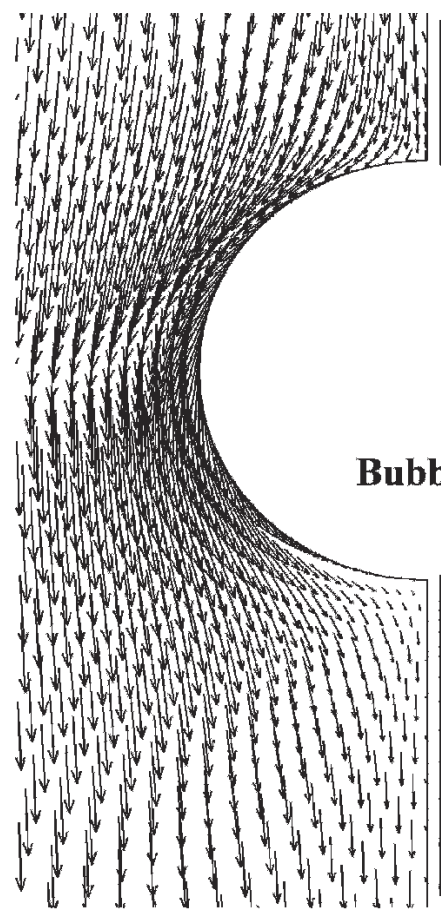

(a)

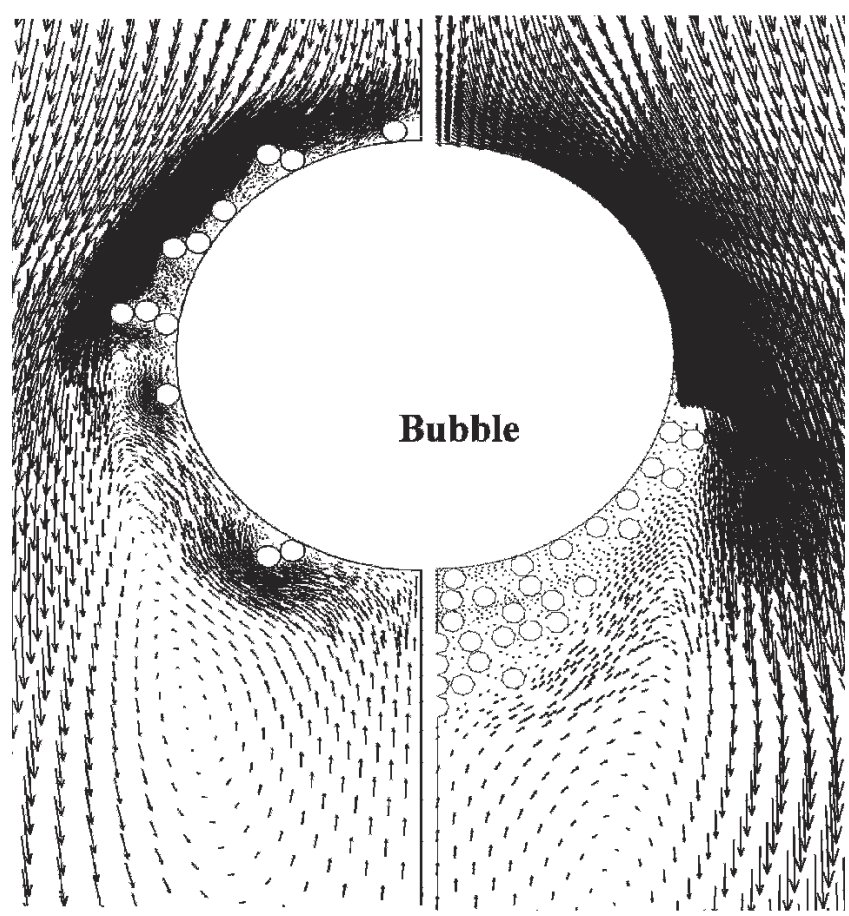

(c)

(d)

Fig. 11-Fluid flow pattern around a 1-mm bubble with $(a) 0,(b) 5,(c) 12$, and $(d) 2850-\mu \mathrm{m}$ inclusions attached.

function of bubble size and inclusion size, according to Eq. [17]. If bubble size is less than $6 \mathrm{~mm}$, smaller bubbles and larger inclusions have larger attachment probabilities. Small 1-mm bubbles can have inclusion attachment probabilities as high as 30 pct, while the inclusion attachment probability to bubbles larger than $5 \mathrm{~mm}$ is less than 1 pct. 


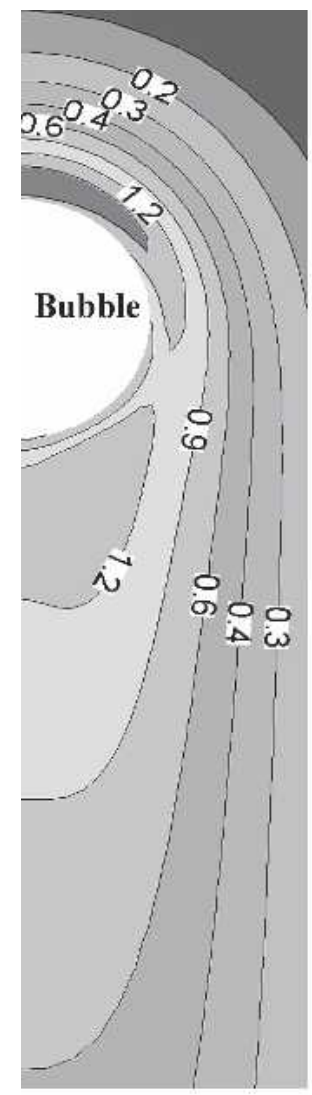

(a)

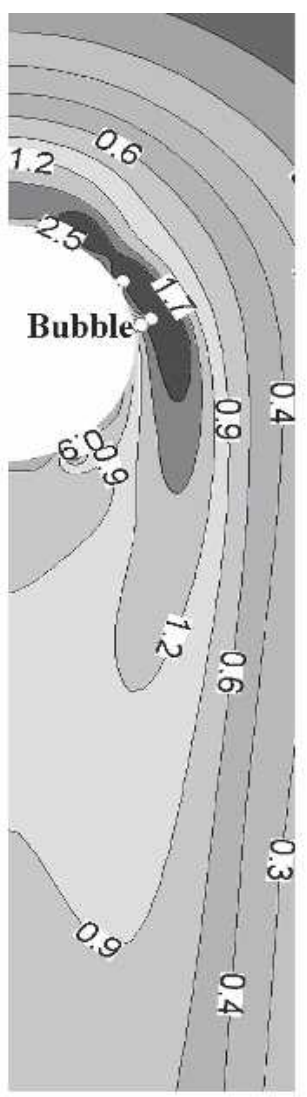

(b)

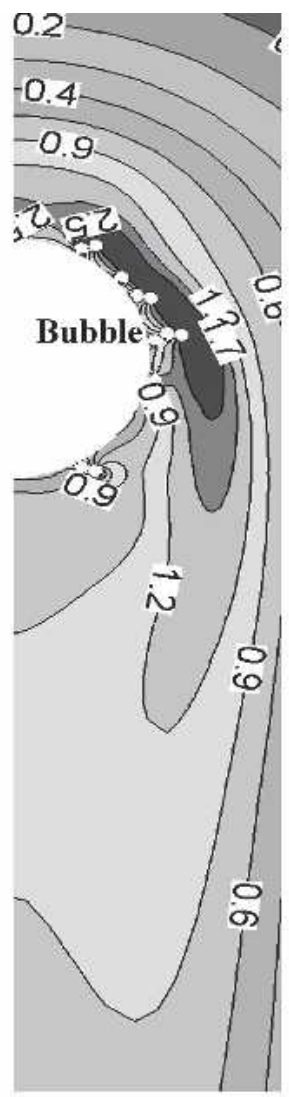

$(c)$

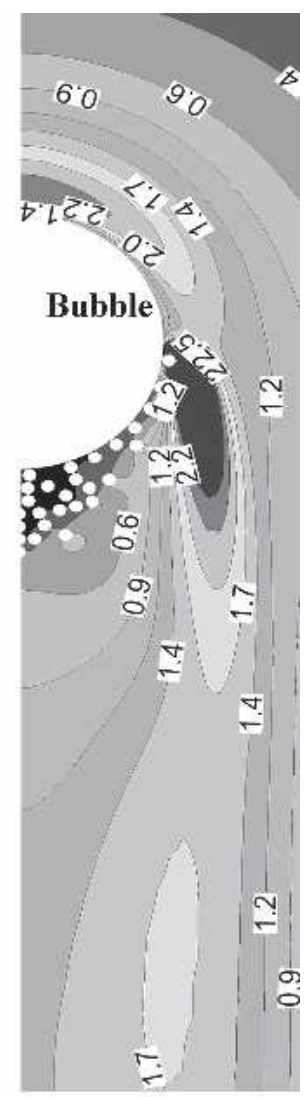

(d)

Fig. 12-Turbulent energy distribution $\left(1000 \mathrm{k} \mathrm{in} \mathrm{m}^{2} / \mathrm{s}^{2}\right)$ around a $1-\mathrm{mm}$ bubble with $(a) 0,(b) 5,(c) 12$, and $(d) 2850-\mu \mathrm{m}$ inclusions attached.

However, the attachment probability increases with increasing bubble size when bubbles are larger than $7 \mathrm{~mm}$. The shape and the terminal velocity of bubbles around $7 \mathrm{~mm}$ (Figures 5 and 7) dominate the fluid flow and particle motion around the spheroidal bubbles. The simulation indicates that more inclusions are captured by the larger spheroidal bubble than the smaller spherical bubble, which was confirmed again by Aoki et al. ${ }^{[43,46]}$

Typical attachment probabilities of inclusions to a bubble surface including the stochastic effects of the turbulent flow are shown in Table II. The stochastic effect simulated by the random walk method slightly increases the attachment probability of inclusions to the bubble surface. Figure 16 shows that this effect allows $50-\mu \mathrm{m}$ inclusions starting 4 bubble diameters from the column axis to collide and attach to the 1-mm bubble surface. The largest attachment opportunity is at $\sim 2 \mathrm{~mm}$ diameter. On the other hand, the simulation indicates that without considering the stochastic effect, which means ignoring the random walk model (Figure 4(a)), all of the $50-\mu \mathrm{m}$ inclusions injected within $0.34 \mathrm{~mm}$ of the column axis attach to the bubbles, and inclusions injected outside $0.34 \mathrm{~mm}$ of the column axis will not touch the bubble at all. Owing to the extra computational effort required for the stochastic model, it was not performed for all sizes of bubbles and inclusions. The stochastic attachment probability was estimated from the two cases to be $16.5 / 11.6=1.4$ times of the non-stochastic attachment probability.

\section{FLUID FLOW AND BUBBLE MOTION IN THE CONTINUOUS CASTING STRAND}

\section{A. Model Formulation and Flow Pattern}

Three-dimensional single-phase steady turbulent fluid flow in the SEN and continuous casting strand was modeled by solving the continuity equation, Navier-Stokes equations, and standard equations for transport of turbulent energy and its dissipation rate. ${ }^{[47,48]}$ The trajectories of bubbles are calculated by Eqs. [12] through [15], which include the effect of chaotic turbulent motion using the random walk model. Inclusion trajectories calculated with this approach match reasonably well with those by large eddy simulation. ${ }^{[49]}$ Bubbles escape at the top surface and the open bottom of the 2.55$\mathrm{m}$-long mold domain and are reflected at other faces. Bubbles that escape from the bottom are considered to eventually become entrapped by the solidifying shell. This is a crude preliminary approximation of flow and bubble transport, which is being investigated further as part of this project. ${ }^{[50]}$ The entrapment of particles into the solidifying shell is very complex and is receiving well-deserved attention in recent work. ${ }^{[51,52,53]}$

The SEN has an $80-\mathrm{mm}$ bore size, a down 15-deg outport angle, and a $65 \times 80-\mathrm{mm}$ outport size. The submergence depth of the SEN is $300 \mathrm{~mm}$ and the casting speed is $1.2 \mathrm{~m} / \mathrm{min}$, corresponding to a steel throughput of 3.0 tonne/min. Halfwidth of the mold is simulated in the current study $(0.65 \mathrm{~m}$ half width $\times 0.25 \mathrm{~m}$ thickness). The calculated weighted 


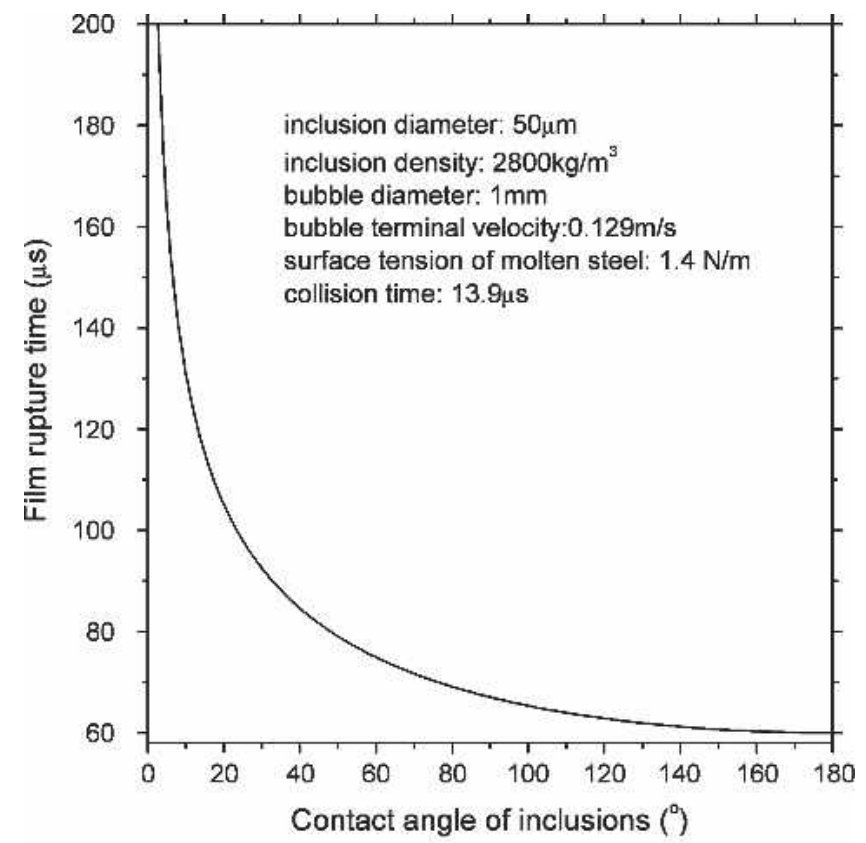

(a)

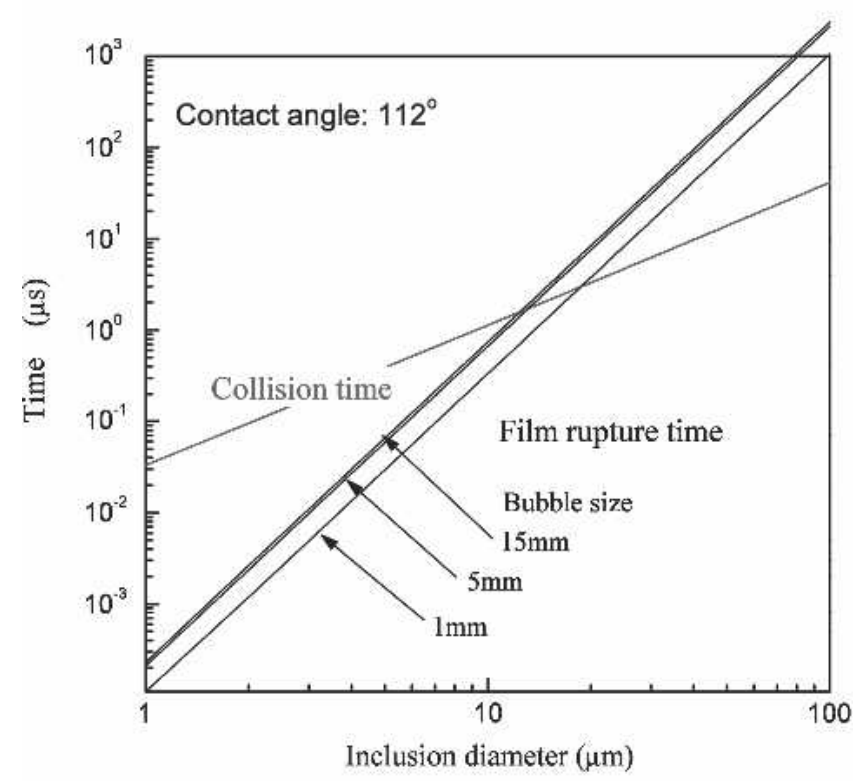

(b)

Fig. 13-The collision time and film drainage time of inclusions onto different-size bubbles.

average turbulent energy and its dissipation rate at the SEN outport are $0.20 \mathrm{~m}^{2} / \mathrm{s}^{2}$ and $5.27 \mathrm{~m}^{2} / \mathrm{s}^{3}$, respectively. The argon flow rate injected into the molten steel through the upper nozzle and upper slide gate is 10 to $15 \mathrm{Nl} / \mathrm{min}$. According to previous multiphase fluid flow simulation, ${ }^{[54]}$ under this argon gas flow rate, the fluid flow pattern in the current mold is still a double roll flow pattern. However, if the argon gas flow rate is much larger, the fluid flow pattern in the mold will become single roll. ${ }^{[48,55]}$ Thus, the current simplification that ignores momentum transfer from the bubbles to the fluid just roughly represents the real multiphase fluid flow in this mold. In the further investigation, the two-phase fluid flow will be calculated.

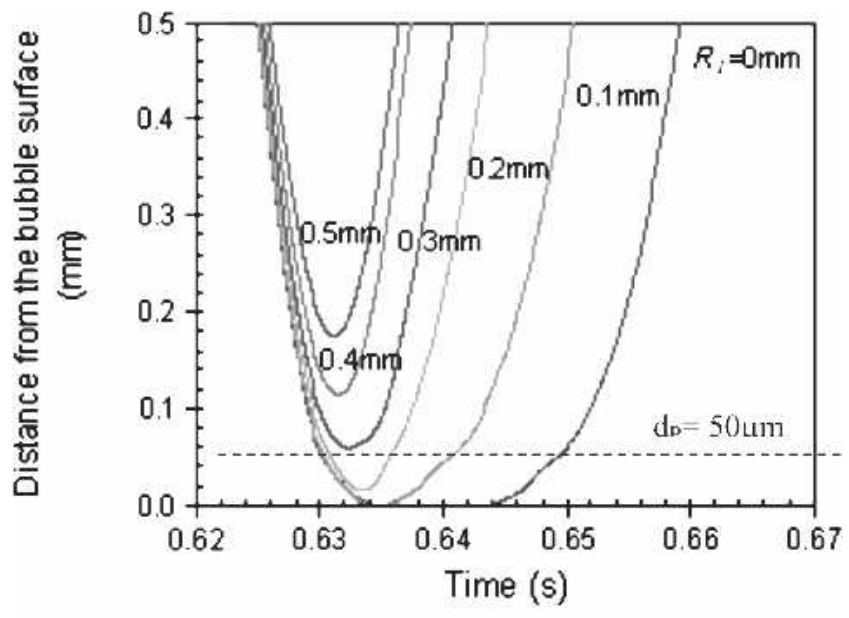

(a)

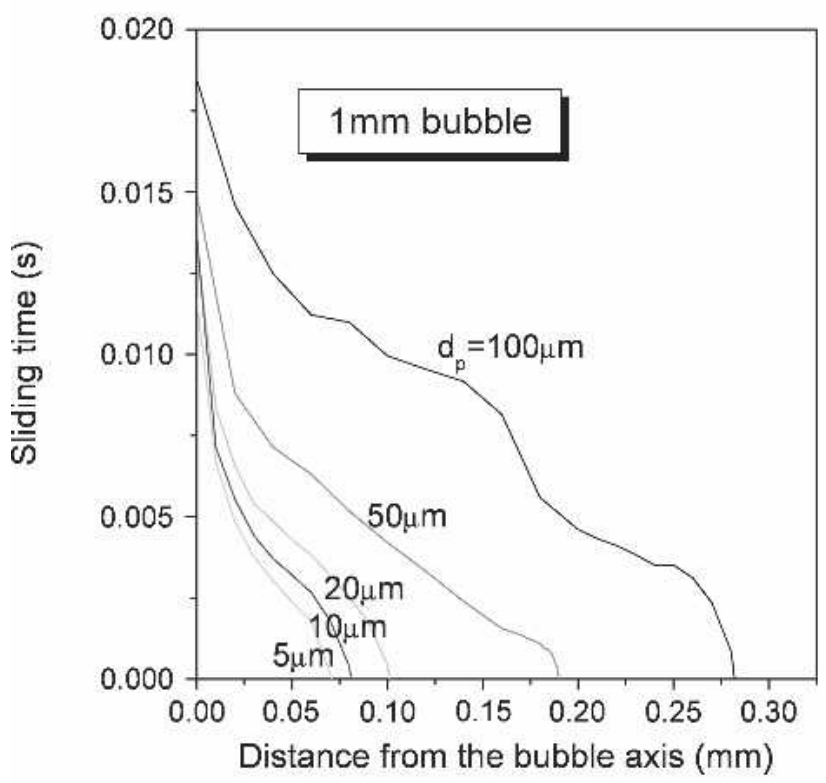

(b)

Fig. 14-Computed normal distance from the center of $100-\mu \mathrm{m}$ inclusions to the surface of a 1-mm bubble $(a)$ and interaction times $(b)$.

The velocity vector distribution on the center face of the half-strand is shown in Figure 17, indicating a double roll flow pattern. The upper loop reaches the meniscus of the narrow face, and the second loop takes steel downward into the liquid core and eventually flows back toward the meniscus in the strand center. The calculated volumeaverage turbulent energy and its dissipation rate in the CC strand are $1.65 \times 10^{-3} \mathrm{~m}^{2} / \mathrm{s}^{2}$ and $4.22 \times 10^{-3} \mathrm{~m}^{2} / \mathrm{s}^{3}$, respectively.

\section{B. Bubble Trajectory Results}

Typical bubble trajectories are shown in Figure 18. Smaller bubbles penetrate and circulate more deeply than the larger ones. According to Figure 6, the maximum bubble size is around $5 \mathrm{~mm}$. Bubbles larger than $1 \mathrm{~mm}$ mainly move in the upper roll and are quickly removed. Bubbles with a size of $0.2 \mathrm{~mm}$ can recirculate with paths as long as 


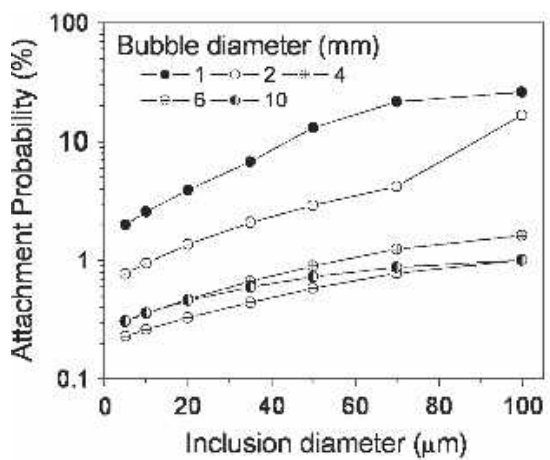

Numerical simulation (NS)

(a)
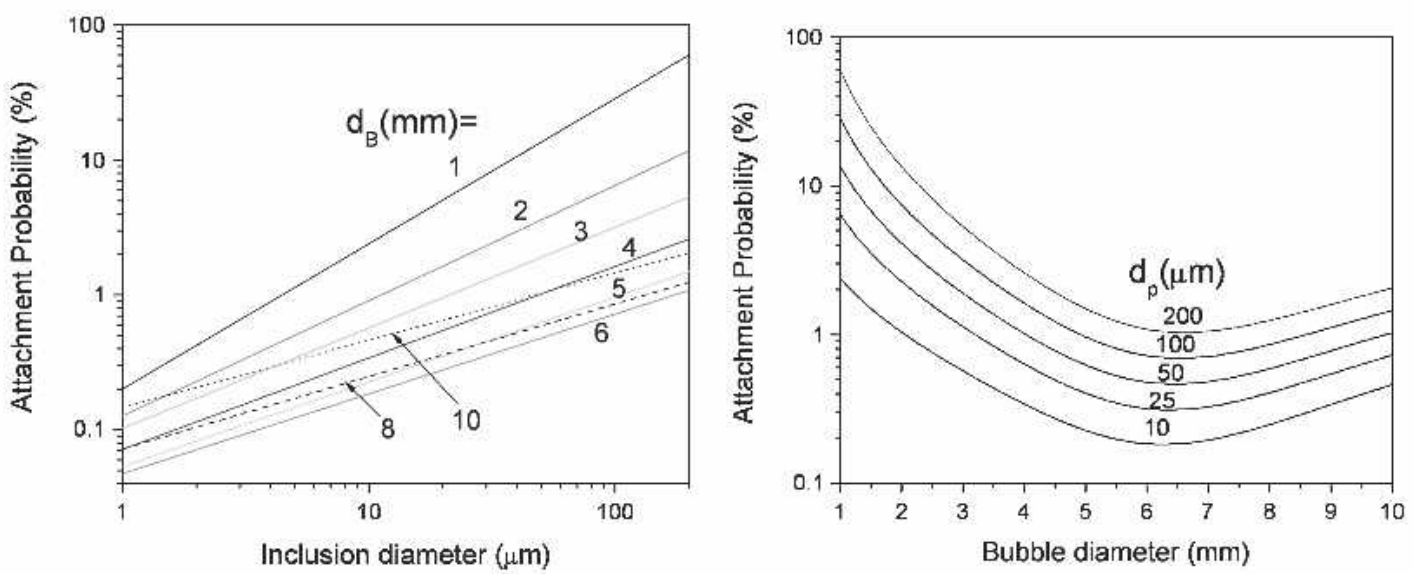

Attachment probability as function of inclusion size and bubble size (regression Eq.17) Comparison of numerical simulation and regression Eq.17

(b)

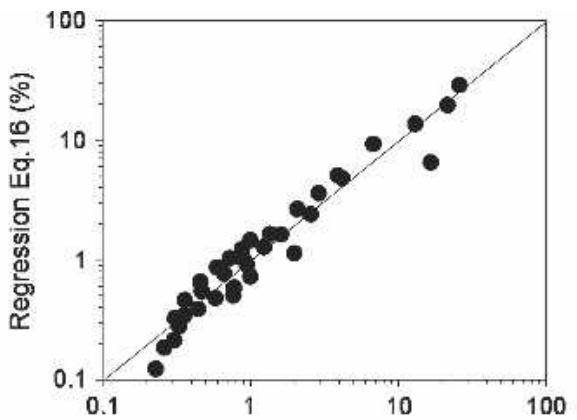

Numerical simulation of attachment probability (\%)

(c)

Fig. 15-Calculated attachment probability of inclusions to bubbles.

$6.65 \mathrm{~m}$ and $71.5 \mathrm{~s}$ before they escape from the top or become entrapped through the bottom, while $0.5-\mathrm{mm}$ bubbles move $3.34 \mathrm{~m}$ and $21.62 \mathrm{~s}, 1-\mathrm{mm}$ bubbles move $1.67 \mathrm{~m}$ and $9.2 \mathrm{~s}$, and $5-\mathrm{mm}$ bubbles move $0.59 \mathrm{~m}$ and $0.59 \mathrm{~s}$. The mean path length $\left(L_{B}\right)$ and the residence time $\left(t_{B}\right)$ of 5000 bubbles of each size are shown in Figure 19, and the following regression equations are obtained:

$$
L_{B}=9.683 \exp \left(-\frac{1000 d_{B}}{0.418}\right)+0.595
$$

$$
\begin{aligned}
t_{B}= & 195.6 \exp \left(-\frac{1000 d_{B}}{0.149}\right)+23.65 \exp \left(-\frac{1000 d_{B}}{0.139}\right) \\
& +2.409 \exp \left(-\frac{1000 d_{B}}{8.959}\right)
\end{aligned}
$$

Combining the path length and the residence time, the apparent average bubble speed is $W_{B}=L_{B} / t_{B}$. The following regression equation is obtained:

$$
W_{B}=0.170\left(1000 d_{B}\right)^{0.487}
$$

Larger bubbles have larger average speed, which can be as high as $0.5 \mathrm{~m} / \mathrm{s}$ for $10-\mathrm{mm}$ bubbles.

\section{INCLUSION REMOVAL BY BUBBLES IN THE CONTINUOUS CASTING STRAND}

\section{A. Model Formulation}

A model of inclusion removal by bubble flotation is developed for the molten steel-alumina inclusion-argon bubble system by evaluating a simple algebraic equation that incorporates the results of the previous sections. The following assumptions are used:

(1) Bubbles all have the same size, and the bubble size and the gas flow rate are chosen independently.

(2) Inclusions have a size distribution and are uniformly distributed in the molten steel, and they are too small to affect bubble motion or the flow pattern.

(3) Only the inclusions removed by bubble flotation are considered. The transport and collision of inclusions are ignored.

(4) Once stable attachment occurs between a bubble and an inclusion, there is no detachment and the inclusion is considered to be removed from the molten steel, owing to the high removal fraction of most bubbles.

The number of inclusions $i, N_{A, i}$, with diameter $d_{p, i}$ that attach to a single bubble (sequence number $j$ ) with 
a diameter of $d_{B}$ during its motion through the molten steel is

$$
N_{A, i}=\left.\left(\frac{\pi}{4} d_{B, j}^{2}\right) L_{B, j} \cdot n_{p, i}\right|_{j} \cdot \frac{P_{i}}{100}
$$

where $L_{B}$ is given by Eq. [20], $P$ (pct) is given by Eq. [17], $\left.n_{p, i}\right|_{j}$ is the number density of inclusions with diameter $d_{p, i}$ when bubble $j$ is injected, which can be represented by the following recursion equation:

$$
\left.n_{p, i}\right|_{j}=\left.n_{p, i}\right|_{j-1} \times \frac{\left(100-P_{i}\right)}{100} \times \frac{\left(\frac{\pi}{4} d_{B}^{2}\right) L_{B}}{V_{M}}
$$

In evaluating this equation, the inclusion number density distribution is updated after the calculation of each individual bubble to account for the significant change in inclusion concentration caused by the simultaneous inclusion removal of many bubbles.

In Eq. [24], the volume of molten steel entering the strand in time $t_{B}$ is given by

$$
V_{M}=\frac{V_{C}}{60} S \cdot t_{B, j}
$$

where $S=$ the area of the slab section $\left(=0.25 \times 1.3 \mathrm{~m}^{2}\right)$.

The number density of inclusions $\left(1 / \mathrm{m}^{3}\right.$ steel) of size $i$ removed by attachment to a single bubble is:

$$
n_{A, i}=\frac{N_{A, i}}{V_{M}}
$$

Table I. Regressed Inclusion Attachment Probability to the Bubble Larger than $1 \mathrm{~mm}$

\begin{tabular}{ll}
\hline Bubble Diameter & $\begin{array}{c}\text { Attachment } \\
\text { Probability }(\mathrm{pct})\end{array}$ \\
\hline $1 \mathrm{~mm}$ & $P=0.189 d_{p}^{1.082}$ \\
$2 \mathrm{~mm}$ & $P=0.125 d_{p}^{0.187}$ \\
$4 \mathrm{~mm}$ & $P=0.0570 d_{p}^{0.722}$ \\
$5 \mathrm{~mm}$ & $P=0.0523 d_{p}^{0.634}$ \\
$10 \mathrm{~mm}$ & $P=0.130 d_{p}^{0.444}$ \\
\hline
\end{tabular}

Assuming that all inclusions are $\mathrm{Al}_{2} \mathrm{O}_{3}$, the oxygen removed by this single bubble $j$ (in ppm) then can be expressed by:

$$
\Delta O_{j}=\sum_{i}\left[n_{A, i}\left(\frac{\pi}{6} d_{p, i}^{3}\right) \frac{\rho_{p}}{\rho} \cdot \frac{48}{102} \cdot 10^{6}\right]
$$

which can be rewritten by inserting Eqs. [23] through [26] into Eq. [27] and rearranging as:

$$
\Delta O_{j}=1.16 \times 10^{5} \cdot \frac{1}{V_{C} S} \frac{d_{B, j}^{2} L_{B, j}}{t_{B, j}} \frac{\rho_{p}}{\rho} \sum_{i}\left(\left.n_{p, i}\right|_{j} \cdot P_{i} \cdot d_{p, i}^{3}\right)
$$

Because it is assumed that all bubbles in the molten steel have the same size, the total number of bubbles with diameter $d_{B}$ entering the molten steel during time $t_{B}$ is

$$
n_{B}=\frac{1}{2} \frac{Q_{G} \cdot \frac{T_{M}}{273}}{\frac{\pi}{6} d_{B}^{3}} t_{B}
$$

where the factor of $1 / 2$ is due to the simulation domain of a half-mold.

The total oxygen removal by all of the bubbles can be expressed by:

$$
\Delta O=\sum_{j=1}^{n_{B}} \Delta O_{j}
$$

\section{B. Results and Discussion}

The inclusion size distributions measured in the tundish above the outlets and in the CC slab are shown in Figure 20(a), together with the calculated size distributions after inclusion removal by bubble flotation for several different bubble sizes. The corresponding inclusion removal fractions are shown in Figure 20(b). If the bubbles are larger than $5 \mathrm{~mm}$, less than 10 pct of the inclusions can be removed by bubble flotation at the gas flow rate of $15 \mathrm{Nl} / \mathrm{min}$. This corresponds to a 3-ppm decrease in total oxygen (Figure 21). Smaller bubbles appear to enable more inclusion removal for the same gas flow rate. Specifically, 1-mm bubbles remove almost all of the inclusions larger than $30 \mu \mathrm{m}$. However, it is unlikely that all of the bubbles that

\begin{tabular}{|c|c|c|c|}
\hline & & Case 1 & Case 2 \\
\hline Average turbulent energy $\left(\mathrm{m}^{2} / \mathrm{s}^{2}\right)$ & & $1.62 \times 10^{-4}$ & $1.06 \times 10^{-8}$ \\
\hline Average turbulent energy dissipation rate $\left(\mathrm{m}^{2} / \mathrm{s}^{2}\right)$ & & $1.43 \times 10^{-3}$ & $2.74 \times 10^{-7}$ \\
\hline Bubble velocity $(\mathrm{m} / \mathrm{s})$ & & 1.292 & 1.620 \\
\hline Bubble diameter $(\mathrm{mm})$ & & 1 & 1 \\
\hline Inclusions diameter $(\mu \mathrm{m})$ & & 50 & 100 \\
\hline \multirow[t]{2}{*}{ Attachment probability (pct) } & Non-stochastic model & 11.6 & 27.8 \\
\hline & Stochastic model & 16.5 & 29.4 \\
\hline
\end{tabular}
are this small could escape from the top surface. Those that are entrapped in the solidifying shell would generate serious defects in the steel product, such as shown in Figures 1 and 2. Increasing bubble size above $\sim 7 \mathrm{~mm}$ produces less change in the removal rate because the change in bubble shape offsets the smaller number of bubbles.

Table II. Attachment Probabilities of Inclusions With and Without Random Walk to a 1-mm Bubble 

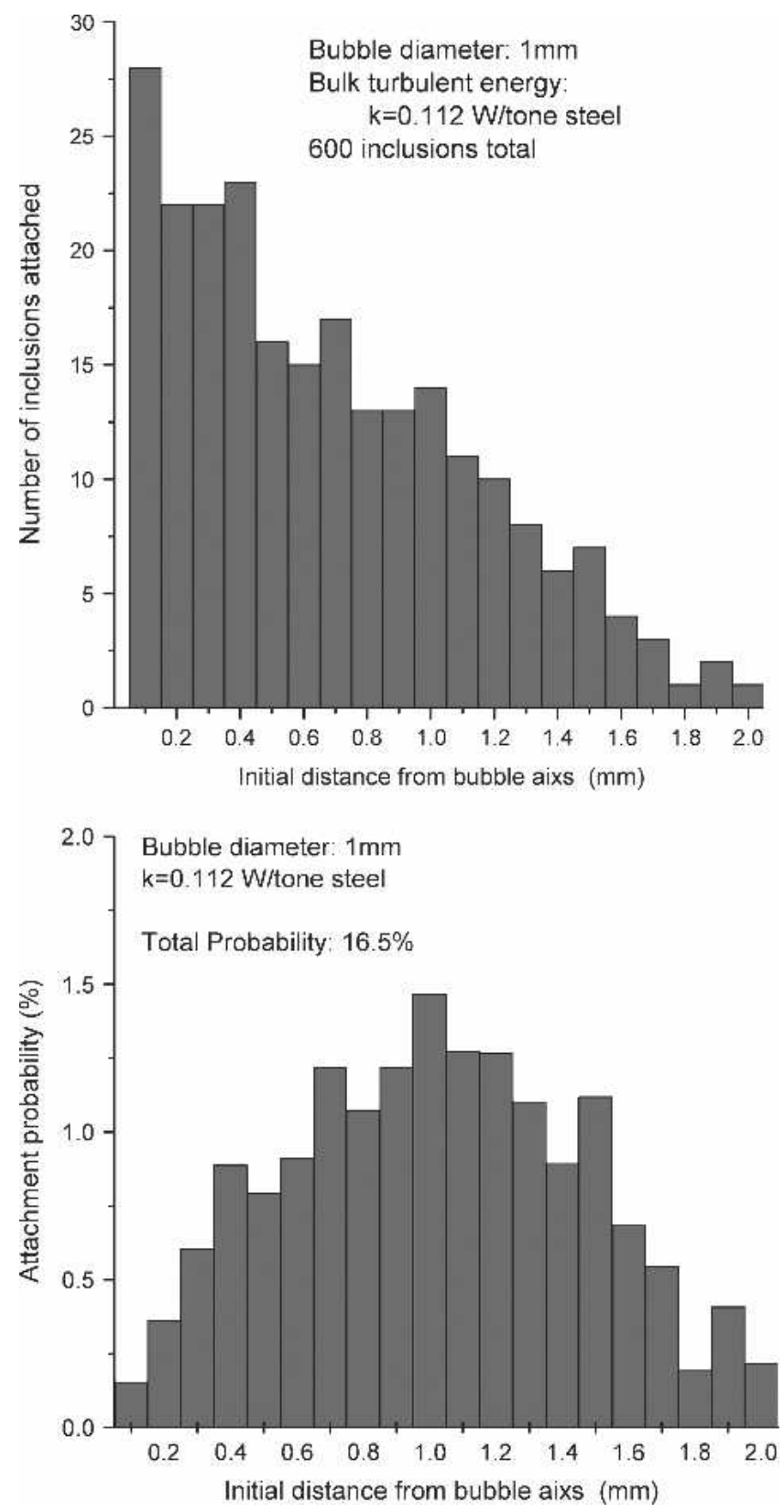

Fig. 16-Attachment probability of $50-\mu \mathrm{m}$ inclusions to a $1-\mathrm{mm}$ bubble including the stochastic effect of turbulence.

Increasing gas flow rate naturally causes more inclusion removal by bubble flotation (Figure 21). Considering the effect of turbulent stochastic motion slightly increases inclusion removal by bubble flotation. For the current CC conditions, including a gas flow rate of $15 \mathrm{Nl} / \mathrm{min}$, the bubble size is likely to be around $5 \mathrm{~mm}$, assuming there are a large number of active sites on the porous refractory that cause a gas flow rate of less than $0.5 \mathrm{~mL}$ per pore. ${ }^{[56]}$ As shown in Figure 21, about 10 pct total oxygen is removed by bubble flotation. Previous investigations indicate that $\sim 8$ pct of the inclusions are removed to the top surface due to flow transport in the CC mold region. ${ }^{[57]}$ Thus, the total predicted inclusion removal by flow transport and by bubble flotation is around 18 pct. The measured inclusion mass fraction is $66.8 \mathrm{ppm}$ in the tundish and averages $51.9 \mathrm{ppm}$ in the slab, which corresponds to 22 pct removal in the mold (Figure 20(a)). The prediction and the measurement agree roughly well, considering that some inclusions are likely entrapped to the SEN walls to cause clogging and others float to the slag layer without the aid of bubbles.

Decreasing bubble size is shown in Figures 20 and 21 to be more efficient at removing inclusions. As mentioned before, however, small bubbles, such as those smaller than $1 \mathrm{~mm}$, may be trapped into the solidifying shell while moving through the lower recirculation zone. Thus, there should be an optimal bubble size that gives not only high inclusionremoval efficiencies but also low entrapment rates. The present results suggest the optimal size might be from 2 to $4 \mathrm{~mm}$.

Due to capturing many inclusions on its surface, the apparent density of a bubble with attached inclusions increases. According to the current fluid flow and inclusions condition in the CC mold, the calculated apparent density of the bubble decreases with increasing bubble size (Figure 22(a)). The maximum apparent bubble density is only around $5.0 \mathrm{~kg} / \mathrm{m}^{3}$. Although this is much greater than the original argon gas density of $1.6228 \mathrm{~kg} / \mathrm{m}^{3}$, it is still far smaller than that of the molten steel, so it has little effect on the bubble motion or bubble residence time in the strand (Eq. [12]). The inclusions attached to each bubble also have a size distribution (Figure 22(b)). There are typically several thousand inclusions predicted to be attached to the bubble surface, which matches well with the measurements in Figure 22(c). Larger bubbles capture more inclusions than smaller ones (Figure 22(b)) per bubble. This is insufficient to make up for their smaller number, however, and furthermore makes them more dangerous if captured. Thus, large bubbles should be avoided.

\section{FUTURE FURTHER STUDY: EFFECT OF TURBULENCE}

The effect of turbulence on the fluid flow near the bubble surface, the motion of inclusions near the bubble surface, and the terminal velocity of bubbles should be further investigated in the future. Pan et al. measured the removal of particles (100 to $800 \mu \mathrm{m}$ in size) by bubble flotation in a water model by analyzing high-speed camera photos. ${ }^{[1]}$ Zhang et al. studied inclusion removal by bubble flotation in a water model under turbulent conditions by measuring the particle number density (i.e., size distribution) using a Coulter Counter. ${ }^{[6]}$ Several other papers model the contribution of turbulence to the attachment of inclusions to bubbles in a water system in terms of the turbulent energy dissipation rate. Schubert considered that the interaction between bubble and solid particles in water is just like the turbulent collision process of particles with similar sizes, and reported the following attachment probability $P^{[58]}$

$$
P \propto \varepsilon^{4 / 9}\left[\left(C_{1} d_{P}^{7 / 9}\right)^{2}+\left(C_{2} d_{B}^{7 / 9}\right)^{2}\right]^{1 / 2}
$$

This equation can be used only if:

$$
d_{p}, d_{B} \geq 15\left(\nu^{3} / \varepsilon\right)^{1 / 4}
$$

For metallurgical melts, the typical value of $\varepsilon$ is 0.0001 to $1 \mathrm{~m}^{2} / \mathrm{s}^{3}$, so this equation can be used only if $d_{p}, d_{B}$ 


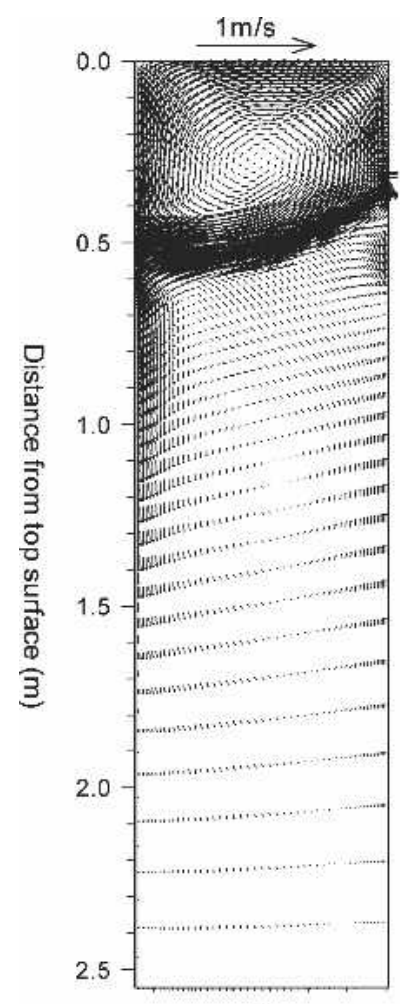

(a)

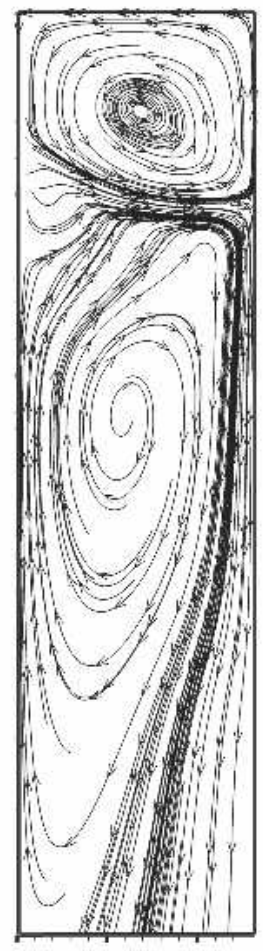

(b)

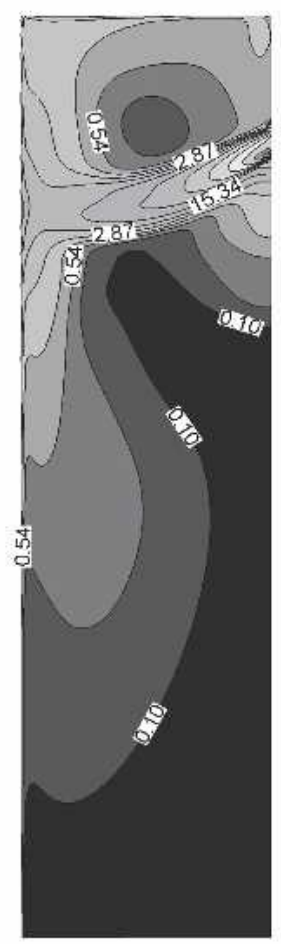

(c)

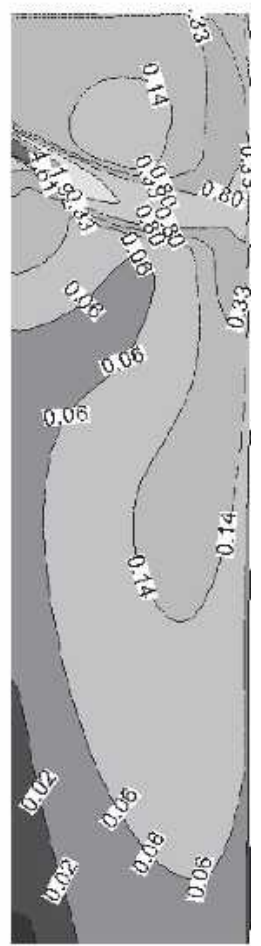

(d)

Fig. 17-Flow pattern in the CC strand center face with half-width. (a) Velocity vectors. (b) Streamline. (c) Turbulent energy dissipation rate $1000 \varepsilon \mathrm{m}^{2} / \mathrm{s}^{3}$. (d) Turbulent energy $100 \mathrm{k} \mathrm{m}^{2} / \mathrm{s}^{2}$.

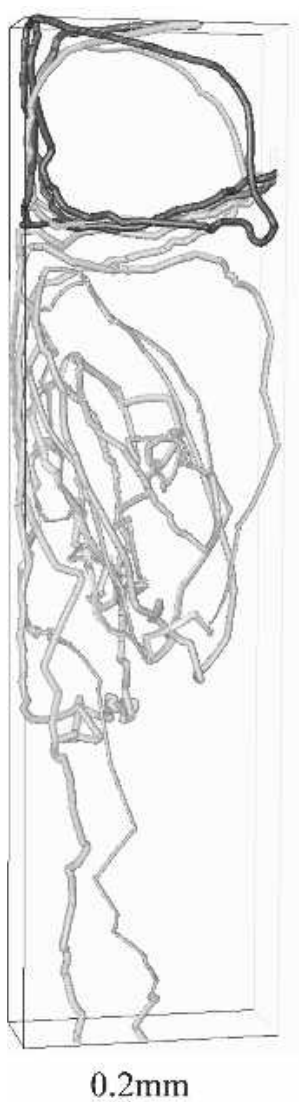

(a)

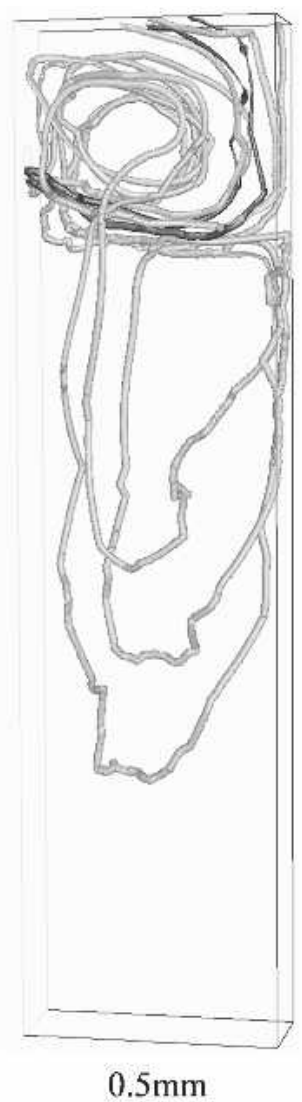

(b)

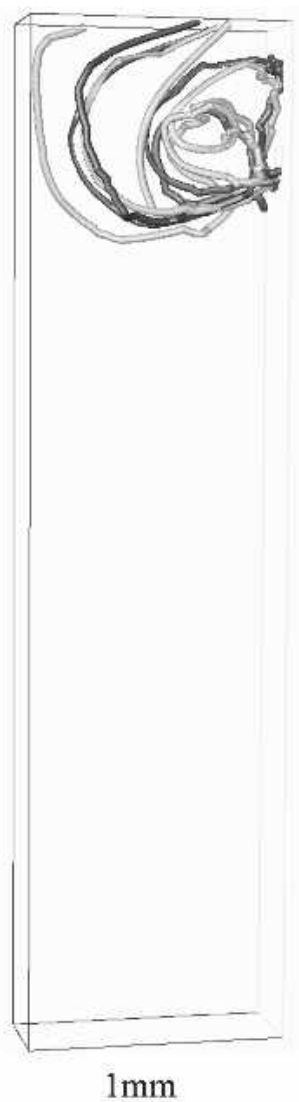

(c)

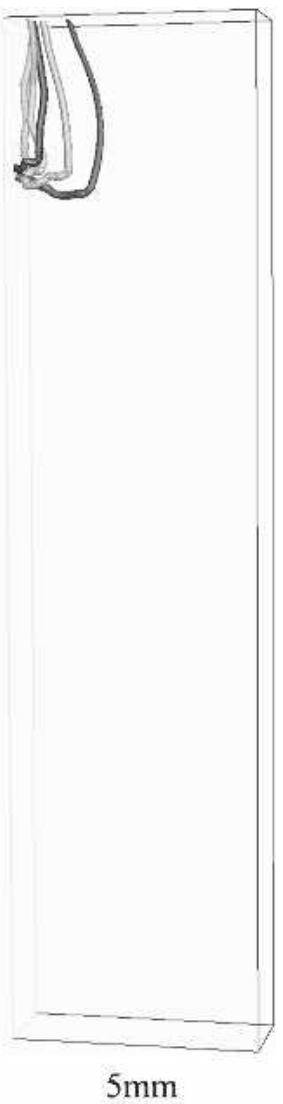

(d)

Fig. 18-Typical bubble trajectories in the mold with half-width. 


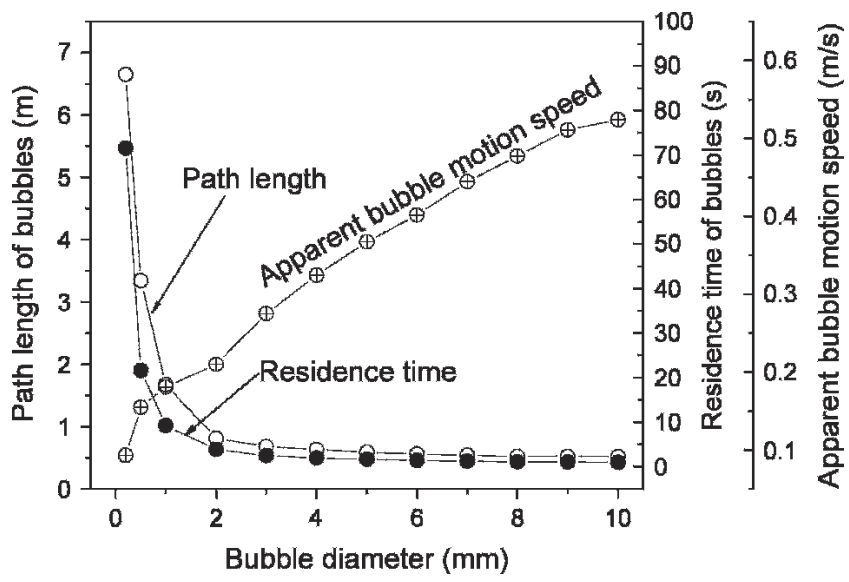

Fig. 19-Mean path lengths, residence times, and apparent speed of bubbles in the CC strand.

$\geq 458 \mu \mathrm{m}$. Zhang et al. derived the following attachment probability with extensive water model experiments: ${ }^{[6]}$

$$
P \propto\left(d_{p} / d_{B}\right)^{2.65} \varepsilon^{0.104} Q_{G}^{1.630}
$$

The model for inclusion motion in the boundary layer near the bubble surface also needs to be further developed.

In the current study, the terminal velocity of the bubble is that in the quiescent liquid. In the continuous casting, as shown in Figure 17, the inlet jet has a much higher speed than the bubble terminal speed. The relative velocity between the bubble and the liquid steel and the relative velocity between the bubble and the inclusion in the liquid steel should be used, but not the terminal velocity in the quiescent liquid. In other words, the bubble local velocity and speed in the mold will be quite different as the terminal velocity in the quiescent liquid. Figure 23 shows the calculated bubble local speed and velocity when they move in the mold as shown in Figure 18, also compared with the speed and velocity of the solute particles. Smaller bubbles move more with the fluid flow, and large bubbles have a clearly different velocity from the fluid flow. When considering the turbulent fluctuation (stochastic model), the bubble velocity is very different from that ignoring the turbulent fluctuation. Figure 23 shows that the bubble velocity and speed are very local, depending on the local fluid flow velocity and local turbulent energy. This and its effect on the interaction between the bubble and the inclusion need to be further studied in the future.

\section{SUMMARY AND CONCLUSIONS}

This work presents a fundamental approach to modeling inclusion removal due to bubble flotation in molten steel processing. The problem of multiple length and time scales is addressed by dividing the modeling into two modeling stages: fundamentals of inclusion-bubble interactions that are independent of the macroscale process, and macroscale flow phenomena that can incorporate the results of the microscale effects. The small-scale model is validated with available measurements and applied to predict the changes

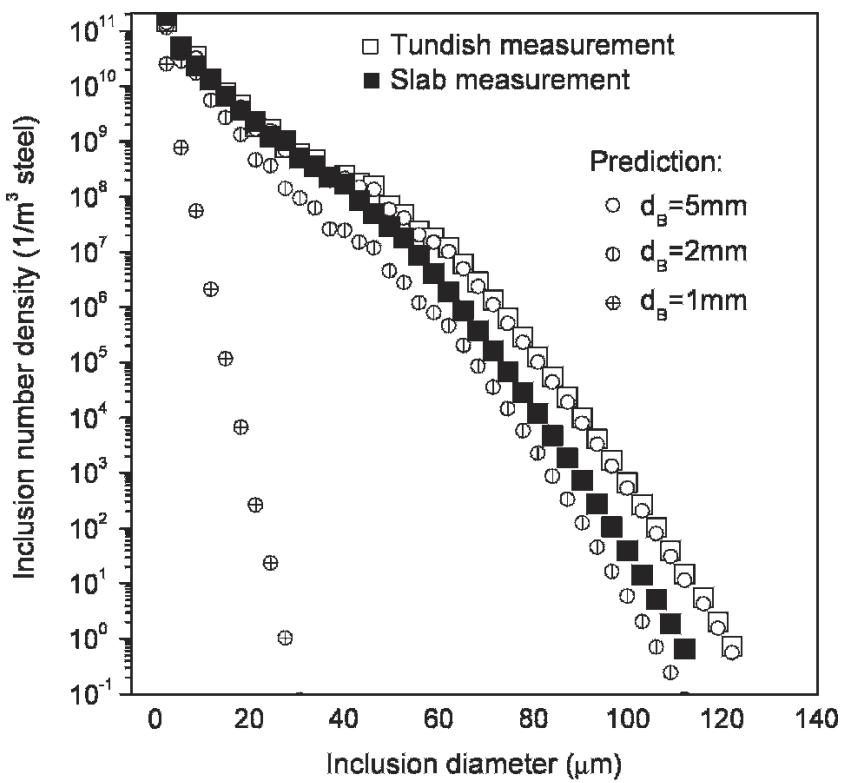

(a)

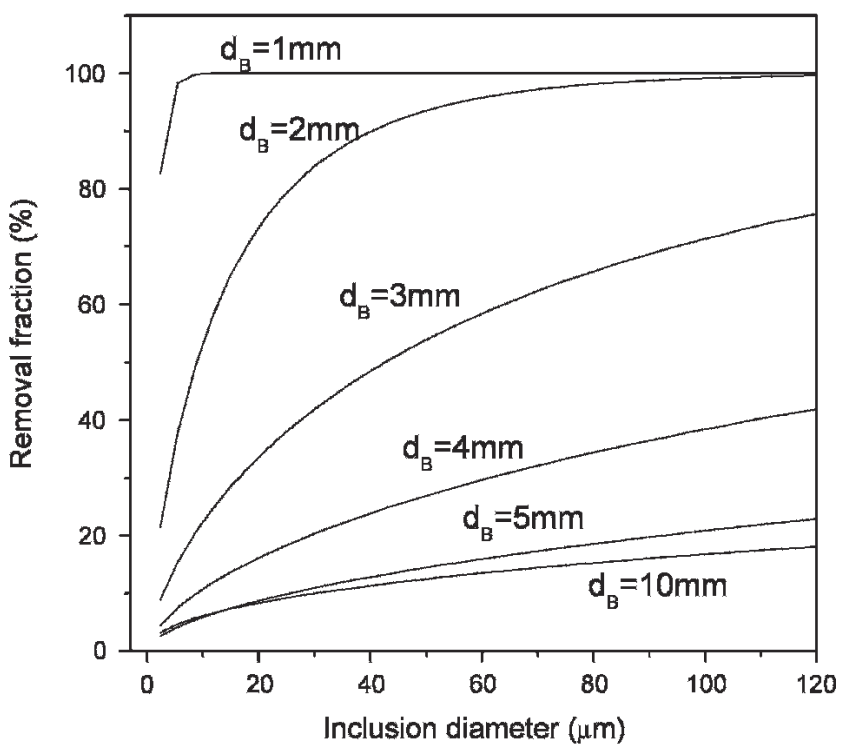

(b)

Fig. 20-Measured and calculated inclusion size distribution with different size bubble flotation ( $15 \mathrm{Nl} / \mathrm{min}$ gas).

in inclusion distribution that occur in the mold region of a continuous slab caster. Specific model findings include:

1. In molten steel, bubbles smaller than $3 \mathrm{~mm}$ tend to be spherical, 3- to $10-\mathrm{mm}$ bubbles are spheroidal, and bubbles larger than $10 \mathrm{~mm}$ are spherical-cap-shaped. The bubble size depends mainly on the gas flow rate, injection method, and stirring power in the molten steel. The average equivalent size of bubbles is estimated to be $\sim 5 \mathrm{~mm}$ in the CC mold investigated in this work.

2. Inclusions tend to pass the midpoint of the bubble and first touch the bubble surface toward the bottom side, although stochastic fluctuations due to turbulence cause many variations. The fluid flow pattern around a bubble 


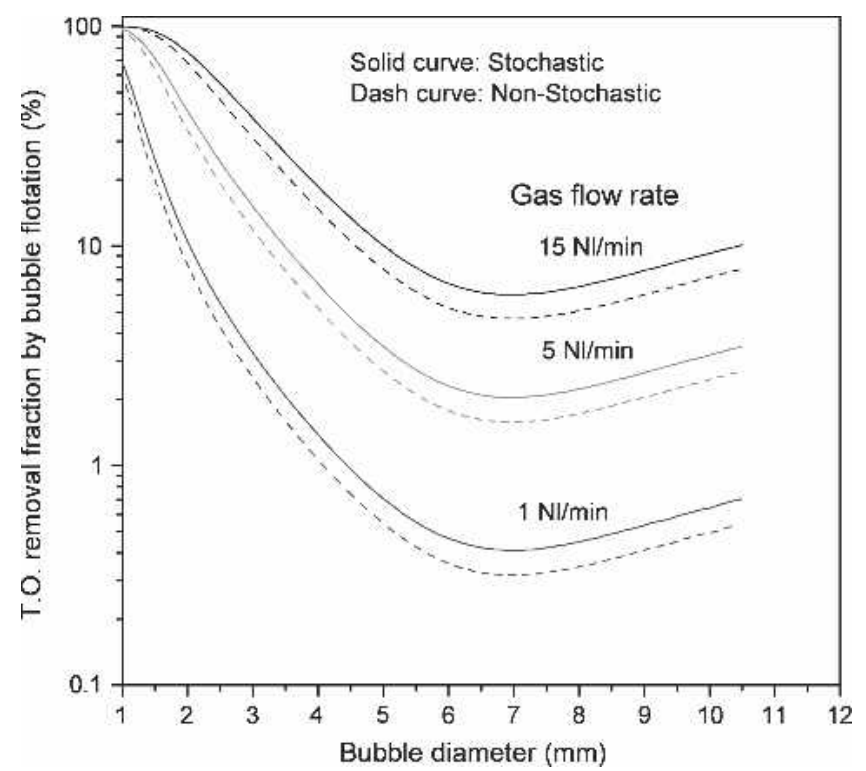

Fig. 21-Calculated inclusion removal by bubble flotation.

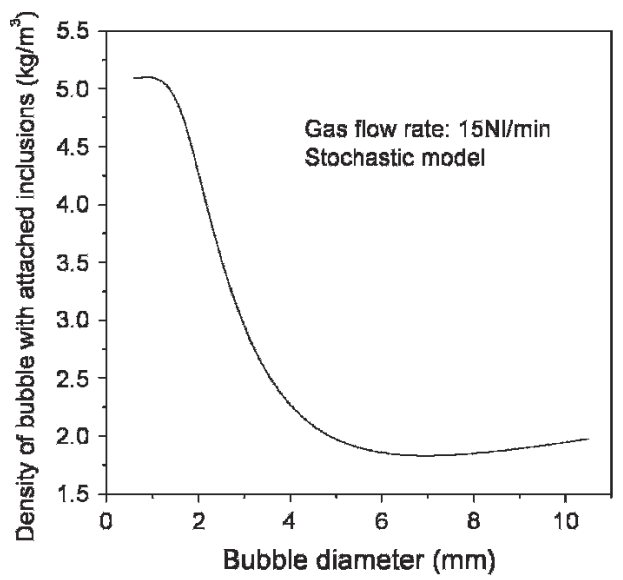

(a) with attached solid inclusions is similar to that of flow around a large solid particle. Inclusions attached to the bubble surface also increase the turbulent kinetic energy distributed around the bubble.

3. Smaller bubbles and larger inclusions have larger attachment probabilities. Bubbles smaller than $1 \mathrm{~mm}$ in diameter have inclusion attachment probabilities as high as $30 \mathrm{pct}$, while the inclusion attachment probability for bubbles larger than $5 \mathrm{~mm}$ is less than 1 pct. The stochastic effect of turbulence (modeled by the random walk method) slightly increases the attachment rate.

4. In the continuous casting strand, smaller bubbles penetrate and circulate more deeply than larger ones. Bubbles larger than $1 \mathrm{~mm}$ mainly move in the upper roll, moving 0.6 to $1.7 \mathrm{~m}$ in 0.6 to $9.2 \mathrm{~s}$. Smaller bubbles can move over $6 \mathrm{~m}$ and take over $60 \mathrm{~s}$ before they either escape from the top surface or are entrapped through the bottom.

5. In the continuous casting mold, if the bubbles are $\sim 5 \mathrm{~mm}$ in diameter, $\sim 10 \mathrm{pct}$ of the inclusions are predicted to be removed by bubble flotation, corresponding to a decrease in total oxygen of around $3 \mathrm{ppm}$. Combined

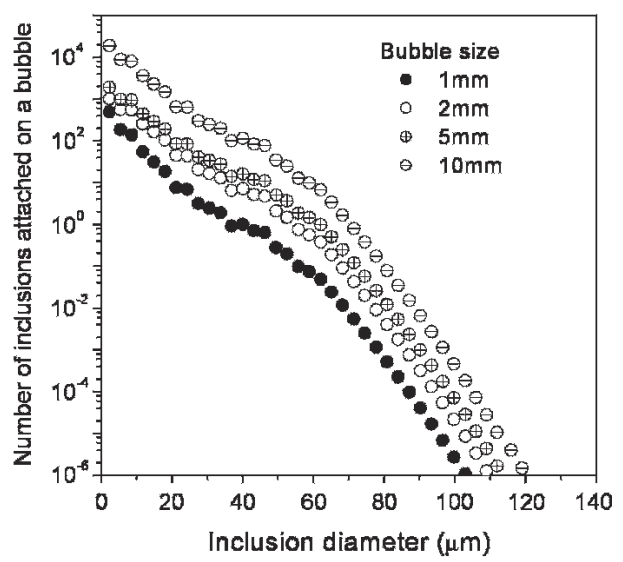

(b)

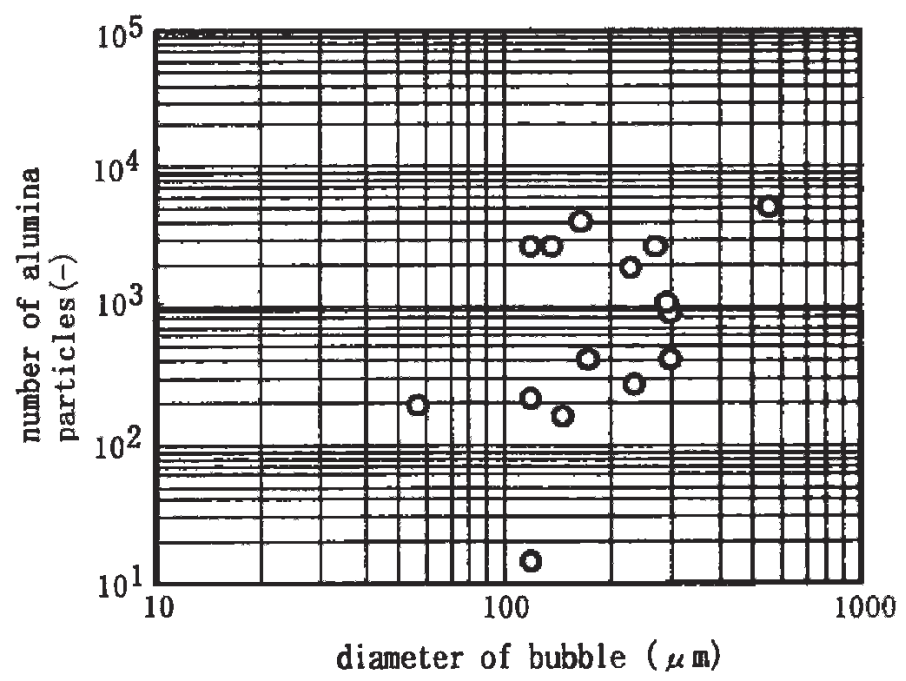

(c)

Fig. 22-The calculated apparent density of bubbles with attached inclusions $(a)$ and the calculated $(b)$ and measured $(c)^{[9]}$ number of inclusions attached on the bubble in the steel. 


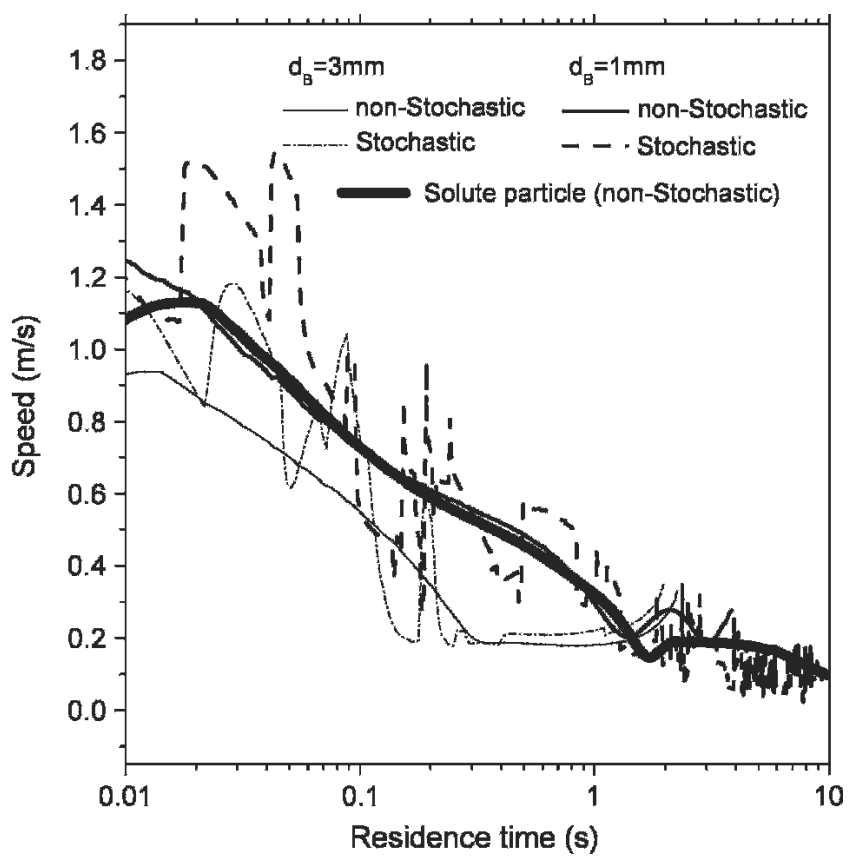

(a)

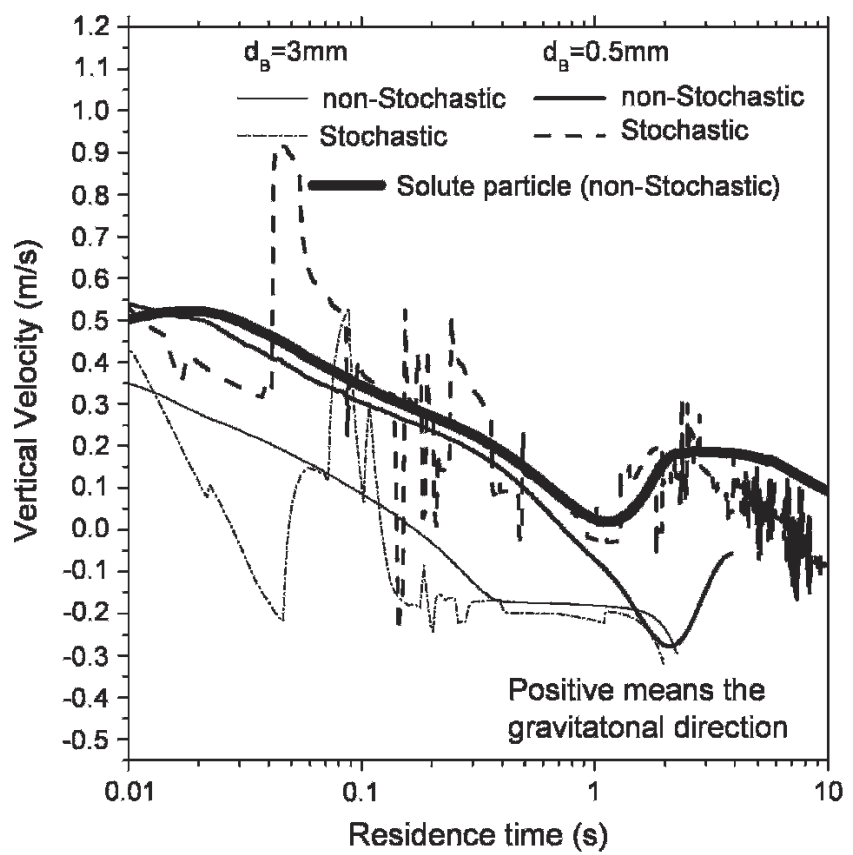

(b)

Fig. 23-Bubble local velocity and speed in the mold.

with $\sim 8$ pct inclusion removal by flow transport, the total is comparable to the measured inclusion-removal rate by the $\mathrm{CC}$ mold of $\sim 22$ pct.

6. Smaller bubbles are more efficient at inclusion removal by bubble flotation, so long as they are not entrapped in the solidifying shell. A higher gas flow rate favors inclusion removal by bubble flotation. The optimal bubble size might be 2 to $4 \mathrm{~mm}$.

7. Attached inclusions increase the bubble density by several times but do not affect its motion because the apparent density is still far smaller than that of molten steel.
Future research using this methodology is needed to investigate:

(1) The stochastic probability of all inclusion and bubble sizes.

(2) The effect of bubble size distribution.

(3) Multiphase fluid flow, including momentum exchange between phases.

(4) The effect of inclusion collisions.

(5) The entrapment of bubbles and inclusions into the solidifying steel shell.

(6) Other process such as inclusion removal by bubble flotation in gas stirred ladles.

\section{ACKNOWLEDGMENTS}

This material is based upon work supported by the U.S. Department of Energy under cooperative agreement number DE-FC36-03ID14279. Such support does not constitute an endorsement by DOE of the views expressed in the article. This research is also supported by the National Science Foundation (Grant DMI-0115486) and the Continuous Casting Consortium at UIUC.

\section{NOMENCLATURE}

$A$

$A_{\mathrm{B}+\mathrm{P}} \quad$ The cross section area of the column with diameter of $d_{B}+2 d_{P}, \mathrm{~m}^{2}$

$A_{i} \quad$ The annular area at which the inclusions are injected, $\mathrm{m}^{2}$

$C$ Dimensionless factor of film rupture time, $C=4$

$C_{1}, \quad C_{2}$ Constant in Eq. [31]

$C_{\mathrm{A}}, \quad C_{\mathrm{B}}$ Constant in Eq. [17]

$C_{\mathrm{D}} \quad$ The dimensionless drag coefficient

$d_{\mathrm{B}} \quad$ Bubble diameter, $\mathrm{m}$ or $\mathrm{mm}$

$d_{\mathrm{Bmax}} \quad$ The maximum bubble size, $\mathrm{m}$

$d_{p} \quad$ Particle diameter, $\mathrm{m}$ or $\mu \mathrm{m}$

$d_{O C} \quad$ The diameter of the column in which inclusions collide with the bubble, $\mathrm{m}$

$d_{O S} \quad$ The diameter of the column in which inclusions attached to the bubble, $\mathrm{m}$

The aspect ratio $e$ of bubbles in molten steel (Figure 5)

Eo

$F_{B}$

$F_{D}$

$g$

$h_{\mathrm{Cr}}$

$k$

$L_{B}$

$N_{A, i}$

$n_{A, i}$,

$n_{\mathrm{B}}$ the Eötvös number, $E o=\frac{g d_{B}^{2}\left(\rho-\rho_{g}\right)}{\sigma}$

The buoyancy force, $\mathrm{N}$

The the drag force, $\mathrm{N}$

The gravitational acceleration, $\mathrm{m} / \mathrm{s}^{2}$

The critical thickness of liquid film for film rupture, $\mathrm{m}$

The local level of turbulent kinetic energy, $\mathrm{m}^{2} / \mathrm{s}^{2}$

The mean path length of 5000 bubbles, $\mathrm{m}$

The number of inclusions $i$ attached to the bubble bubble, $\mathrm{m}^{-3}$

The total number of bubbles $\left(d_{B}\right)$ entering the molten steel during time $t_{B}$
The number of inclusions $i$ attached to the 
The number of inclusions attaching to the bubble

$\left.n_{p, i}\right|_{j}$

The number density of inclusions with diameter $d_{p, i}$ when bubble $j$ is injected, $\mathrm{m}^{-3}$

$N_{T} \quad$ The number of inclusions in the column of fluid swept by the column with diameter $d_{B}+d_{P}$

$P$

The pressure, $\mathrm{N} / \mathrm{m}^{2}$

Attachment probability of inclusions to a bubble

$Q_{G} \quad$ The gas flow, $\mathrm{Nl} / \mathrm{min}$

$R$,

$\operatorname{Re}_{p}$

S

$t$

$t_{B}$

$t_{c}$

$t_{F}$

$t_{I}$

$T_{M}$

$u$

$u_{\mathrm{B}}$

$u_{i}$ and $u_{j}$

$u_{\mathrm{R}}$

$u_{p}$

$\bar{u}$

$u^{\prime}$

$V_{C}$

$V_{\mathrm{m}}$

\section{$W_{B}$}

$W e_{\text {Crit }}$

$x_{i}$ and $x_{j}$

$\alpha$

\section{$\rho$}

$\rho_{P}$

$\rho_{g}$

$\phi$

$\theta$

$\varepsilon$

$\sigma$

\section{$\nu$}

$\mu$

$\delta_{i j}$

$\tau_{i j}$

$\xi$

$\Delta O_{j}$
The total oxygen removed by all bubbles, ppm

\section{REFERENCES}

1. W. Pan, K. Uemura, and S. Koyama: Tetsu to Hagane, 1992, vol. 78 (8), pp. 87-94.

2. L. Wang, H.-G. Lee, and P. Hayes: Steel Res., 1995, vol. 66 (7), pp. 279-86.

3. L. Zhang and S. Taniguchi: Int. Mater. Rev., 2000, vol. 45 (2), pp. 5982.

4. L. Zhang: Modell. Simul. Mater. Sci. Eng., 2000, vol. 8 (4), pp. $463-$ 76.

5. L. Zhang and S. Taniguchi: Fluid flow and particle removal by bubble flotation in a mechanically stirred vessel. Materials Processing in the Computer Age III, 2000, pp. 111-22.

6. L. Zhang and S. Taniguchi: Ironmaking Steelmaking, 2002, vol. 29 (5), pp. 326-36.

7. G. Abbel, W. Damen, G. de Dendt, and W. Tiekink: ISIJ, 1996, vol. 36, pp. S219-22.

8. W.H. Emling, T.A. Waugaman, S.L. Feldbauer, and A.W. Cramb: in Steelmaking Conference Proceedings, vol. 77, Chicago, IL, April 1316, 1997, ISS, Warrendale, PA, 1994, pp. 371-79.

9. L. Kiriha, H. Tosawa, and K. Sorimachi: VCAMP-ISIJ, 2000, vol. 13, p. 120.

10. B.G. Thomas, A. Denissov, and H. Bai: in Steelmaking Conference Proceedings, vol. 80, Chicago, IL, April 13-16, 1997, ISS, Warrendale, PA, 1997, pp. 375-84.

11. J. Knoepke, M. Hubbard, J. Kelly, R. Kittridge, and J. Lucas: in Steelmaking Conference Proceedings, vol. 77, ISS, Warrendale, PA, 1994, pp. 381-88.

12. N. Kasai, H. Mizukami, and A. Mutou: Tetsu to Hagane, 2003, vol. 89 (11), pp. 1120-27.

13. L. Zhang, B. Rietow, K. Eakin, and B.G. Thomas: ISIJ Inter., 2006, vol. 46 , in press.

14. Y. Miki and S. Takeuchi: ISIJ Int., 2003, vol. 43 (10), pp. 1548-55.

15. R. Gass, H. Knoepke, J. Moscoe, R. Shah, J. Beck, J. Dzierzawski, and P.E. Ponikvar: in ISSTech2003 Conference Proceedings, ISS, Warrendale, PA, 2003, pp. 3-18.

16. P. Rocabois, J.-N. Pontoire, V. Delville, and I. Marolleau: in ISSTech2003 Conference Proceedings, ISS, Warrendale, PA, 2003, pp. 995-1006.

17. H. Yin and H.T. Tsai: in ISSTech2003 Conference Proceedings, ISS, Warrendale, PA, 2003, pp. 217-26.

18. H.J. Schulze: in Developments in Mineral Processing, vol. 4, D.W. Fuerstenau, ed., Elsevier, 1984, pp. 65-66.

19. L. Wang, H.-G. Lee, and P. Hayes: ISIJ Int., 1996, vol. 36 (1), pp. 1724.

20. X. Zheng, P. Hayes, and H.-G. Lee: ISIJ Int., 1997, vol. 37 (11), pp. 1091-97.

21. N. Ahmed and G.J. Jamson: Miner. Process. Extr. Metall. Rev., 1989, vol. 5, pp. 77-99.

22. A.G. Szekely: Metall. Trans. B, 1976, vol. 7B (3), pp. 259-70.

23. K. Okumura, M. Kitazawa, N. Hakamada, M. Hirasawa, M. Sano, and K. Mori: ISIJ Inter., 1995, vol. 35 (7), pp. 832-37.

24. P.E. Anagbo and J.K. Brimacombe: Metall. Mater. Trans., 1990, vol. 21B, pp. 637-48.

25. Y. Miki, B.G. Thomas, A. Denissov, and Y. Shimada: Iron and Steelmaker, 1997, vol. 24 (8), pp. 31-38.

26. Y. Ye and J.D. Miller: Int. J. Miner. Process., 1989, vol. 25 (3-4), pp. 199-219.

27. H.J. Schulze: Miner. Process. Extractive Metall. Rev., 1989, vol. 5, pp. 43-76.

28. Y. Xie, S. Orsten, and F. Oeters: ISIJ Int., 1992, vol. 32 (1), pp. 66-75.

29. R.M. Wellek, A.K. Agrawal, and A.H.P. Skelland: AIChE J., 1966, vol. 12 (5), pp. 854-62.

30. Y. Sahai and R.I.L. Guthrie: Metall. Trans. B., vol. 13B (2), pp. 193202.

31. H. Tokunaga, M. Iguchi, and H. Tatemichi: Metall. Mater. Trans. B, 1999, vol. 30B (1), pp. 61-66.

32. M. Iguchi, H. Tokunaga, and H. Tatemichi: Metall. Mater. Trans. B, 1997, vol. 28B (6), pp. 1053-61.

33. H. Bai: Ph.D. Thesis, University of Illinois, 2000.

34. H. Bai and B.G. Thomas: Metall. Mater. Trans. B, 2001, vol. 32B (4), pp. 702-22. 
35. H. Bai and B.G. Thomas: Metall. Mater. Trans. B, 2001, vol. 32B (2), pp. 253-67.

36. W. Damen, G. Abbel and G. de Dendt: Revue de Metallurgie CIT, 1997, vol. 94 (6), pp. 745-50.

37. M. Sevik and S.H. Park: J. Fluids Eng. Trans. AIME, 1973, pp. 53-60.

38. S. Yokoya, S. Takagi, K. Tada, M. Iguchi, K. Marukawa, and S. Hara: ISIJ Int., 2001, vol. 41 (10), pp. 1201-07.

39. S. Yokoya, S. Takagi, S. Ootani, M. Iguchi, and K. Marukawa: ISIJ Int., 2001, vol. 41 (10), pp. 1208-14.

40. S. Yokoya, S. Takagi, M. Kaneko, M. Iguchi, K. Marukawa, and S. Hara: ISIJ Int., 2001, vol. 41 (10), pp. 1215-20.

41. S. Yokoya, S. Takagi, M. Iguchi, K. Marukawa, and S. Hara: ISIJ Int., 2001, vol. 41 (Suppl), pp. S47-51.

42. FLUENT 6.1 Manual. Fluent Inc., Lebanon, NH, 2003.

43. J. Aoki, L. Zhang, and B.G. Thomas: in ICS 2005: The 3rd International Congress on the Science and Technology of Steelmaking, AIST, Warrendale, PA, 2005, pp. 319-22.

44. FLUENT 5.1. Fluent Inc., Lebanon, NH, 2000.

45. R. Clift, J.R. Grace, and M.E. Weber: Bubbles, Drops and Particles. Academics Press, Inc., New York, NY, 1978.

46. J. Aoki: Master Thesis, University of Illinois at Urbana-Champaign, 2006.

47. L. Zhang and B.G. Thomas: in Proceedings of XXIV Steelmaking National Symposium, Mexico, 2003.
48. B.G. Thomas and L. Zhang: ISIJ Inter, 2001, vol. 41 (10), pp. 118193.

49. L. Zhang and B.G. Thomas: Particle Motion with Random Walk Model in k-e Two-Equation Model Compared with LES Simulation. University of Illinois at Urbana-Champaign, Report No. CCC200501, 2005.

50. Q. Yuan, B.G. Thomas, and S.P. Vanka: Metall. Mater. Trans. B., 2004, vol. 35B (4), pp. 703-14.

51. M. Yemmou, M.A.A. Azouni, and P. Casses: J. Cryst. Growth, 1993, vol. 128 (4), pp. 1130-36.

52. J.K. Kim and P.K. Rohatgi: Metall. Mater. Trans. B, 1998, vol. 29A (1), pp. 351-75.

53. D.M. Stefanescu and A.V. Catalina: ISIJ Inter, 1998, vol. 38 (5), pp. 503-05.

54. B.G. Thomas, L. Zhang, and T. Shi: Effect of Argon Gas Distribution on Fluid Flow in the Mold Using Time-Averaged k-e Models, University of Illinois at Urbana-Champaign, Report No. CCC200105, 2001.

55. L. Zhang and B.G. Thomas: ISIJ Inter., 2003, vol. 43 (3), pp. 271-91.

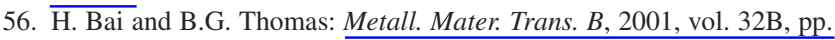
1143-59.

57. L. Zhang, B.G. Thomas, K. Cai, L. Zhu and J. Cui: in ISSTech 2003, ISS, Warrendale, PA, 2003, pp. 141-56.

58. H. Schubert: Int. J. Miner. Process., 1999, vol. 56, pp. $257-76$. 